\title{
A system of evolutionary problems driven by a system of hemivariational inequalities
}

\author{
Lu-Chuan Cenga ${ }^{a}$ Ching-Feng Wen ${ }^{b, *}$, Jen-Chih Yaoc, Yonghong Yaod \\ a Department of Mathematics, Shanghai Normal University, Shanghai 200234, China. \\ ${ }^{b}$ Center for Fundamental Science; and Research Center for Nonlinear Analysis and Optimization, Kaohsiung Medical University, \\ Kaohsiung 80702, Taiwan; Department of Medical Research, Kaohsiung Medical University Hospital, Kaohsiung 80702, Taiwan. \\ ${ }^{c}$ Center for General Education, China Medical University, Taichung 40402, Taiwan. \\ ${ }^{d}$ Department of Mathematics, Tianjin Polytechnic University, Tianjin 300387, China.
}

Communicated by Y.-B. Xiao

\begin{abstract}
In this paper, we introduce the differential system obtained by mixing a system of evolution equations and a system of hemivariational inequalities ((SEESHVI), for short). We prove the superpositional measurability and upper semicontinuity for the solution set of a general system of hemivariational inequalities, and establish the non-emptiness and compactness of the solution set of (SEESHVI).
\end{abstract}

Keywords: Evolution equation, hemivariational inequality, v-condensing mapping, generalized Clarke subdifferential. 2010 MSC: 49K40, 47J20, 49J52.

(C)2018 All rights reserved.

\section{Introduction}

Very recently, Liu et al. [19] formulated a new type of problems that consists of an evolution equation driven by a variational inequality ((EEVI) for short)

$$
\left\{\begin{array}{l}
x^{\prime}(t)=A x(t)+f(t, x(t), u(t)), t \in[0, T], \\
u(t) \in S(K, g(t, x(t), \cdot), \phi), t \in[0, T], \\
x(0)=x_{0},
\end{array}\right.
$$

where $S(K, g(t, x(t), \cdot), \phi)$ stands for the solution set of the following variational inequality: find $u$ : $[0, \mathrm{~T}] \rightarrow \mathrm{K}$ such that

$$
\langle g(t, x(t), u(t)), v-u(t)\rangle_{E_{1}^{*} \times E_{1}}+\phi(v)-\phi(u(t)) \geqslant 0, \forall v \in K
$$

\footnotetext{
*Corresponding author

Email addresses: zenglc@hotmail.com (Lu-Chuan Ceng), cfwen@kmu.edu.tw (Ching-Feng Wen), yaojc@mail.cmu.edu.tw (Jen-Chih Yao), yaoyonghong@aliyun.com (Yonghong Yao)
}

doi: $10.22436 /$ jnsa.011.03.03

Received: 2017-10-06 Revised: 2017-12-03 Accepted: 2017-12-20 
Here, for real Banach spaces $E$ and $E_{1}, K$ is a convex subset of $E_{1}, A: D(A) \subseteq E \rightarrow E$ is the infinitesimal generator of a $C_{0}$-semigroup $e^{A t}$ in $E, \phi: E_{1} \rightarrow \mathbf{R} \cup\{+\infty\}$ is a proper, convex and lower semicontinuous functional, and $f:[0, T] \times E \times E_{1} \rightarrow E$ and $g:[0, T] \times E \times K \rightarrow E_{1}^{*}$ are fixed mappings.

The solutions of problem (EEVI) are understood in the following mild sense.

Definition 1.1. A pair of functions $(x, u)$ with $x \in C([0, T] ; E)$ and $u:[0, T] \rightarrow K$ measurable, is said to be a mild solution of problem (EEVI) if

$$
x(t)=e^{A t} x_{0}+\int_{0}^{t} e^{A(t-s)} f(s, x(s), u(s)) d s, t \in[0, T],
$$

and $u(s) \in S(K, g(s, x(s), \cdot), \phi), s \in[0, T]$. If $(x, u)$ is a mild solution of problem (EEVI), then $x$ is called the mild trajectory and $u$ the variational control trajectory.

It is worth to point out that the aspects related to problem (EEVI), have been until now examined only in a finite dimensional content when $E=\mathbf{R}^{\mathrm{n}}, \mathrm{E}_{1}=\mathbf{R}^{\mathrm{m}}, \mathrm{A}=0$ (see Gwinner $[9,10]$, Li et al. [14], and Pang and Stewart [25]). Liu et al. [17] devoted to the case $E=\mathbf{R}^{n}, E_{1}=\mathbf{R}^{\mathrm{m}}, A=0$, and $f(t, x(t), u(t))=g(t, x(t))+B(t, x(t)) u(t)$. Actually, in these works an ordinary differential equation is parameterized by an algebraic variable required to solve a finite-dimensional variational inequality in the state variable of the differential equation. Such problems taking into account simultaneously both dynamics and constraints in the form of inequalities arise in various situations such as electrical circuits with ideal diodes, Coulomb friction problems for contacting bodies, economical dynamics, dynamic traffic networks, control systems. For more details we refer to [3, 9-11, 14, 16, 17, 25, 27].

On the other hand, Panagiotopulos [23] first introduced the concept of hemivariational inequality concerning nonsmooth and nonconvex energy functions, which is an important generalization of variational inequality. As a useful tool, this type of inequalities and their systems have been used to describe many important problems arising in mechanics and engineering, such as unilateral contact problems in nonlinear elasticity, thermoviscoelastic frictional contact problems, and obstacles problems; see, e.g., [21, 22]. By using the generalized directional derivative (in the sense of Clarke) and the generalized Clarke subdifferential, a growing number of scholars have made fruitful achievements on many kinds of hemivariational inequalities and systems of hemivariational inequalities, including stationary hemivariational inequalities, evolutionary hemivariational inequalities and their systems. For more details on these topics, we can refer to, e.g., [1, 2, 20-22, 24, 26, 28, 30-33] and the references therein.

There are two kinds of important approaches to studying the existence of solution to various types of hemivariational inequalities in the recent literature on hemivariational inequalities. One is closely related to KKM theorems and fixed point theorems, which are used by Panagiotopulos [24], Repovs and Varga [26], Costea and Radulescu [4], and Zhang and He [35] to study stationary hemivariational inequalities and systems of stationary hemivariational inequalities. The other is closely related to surjectivity theorems concerning pseudomonotone and coercive operators, which are captured by Xiao and Huang [29], and Liu [15] for various types of stationary hemivariational inequalities and evolutionary hemivariational inequalities. Very recently, Xiao et al. [31] studied a system of time-dependent hemivariational inequalities with Volterra integral terms by using a surjectivity theorem for pseudomonotone and coercive operators, and the Banach fixed-point theorem for contraction maps. Under some appropriate conditions, the existence result of solution to the problem considered was established by proving that a derived vector inclusion problem with Volterra integral term is solvable.

Inspired by the above problem (EEVI), we formulate a new type of problems that consists of a system of evolution equations driven by a system of hemivariational inequalities ((SEESHVI), for short)

$$
\left\{\begin{array}{l}
x_{1}^{\prime}(t)=A_{1} x_{1}(t)+f_{1}(t, x(t), u(t)), t \in[0, T], \\
x_{2}^{\prime}(t)=A_{2} x_{2}(t)+f_{2}(t, x(t), u(t)), t \in[0, T], \\
\left(u_{1}, u_{2}\right) \in S\left(K_{1}, g_{1}, J_{1}^{\circ}, \phi_{1}\right) \times S\left(K_{2}, g_{2}, J_{2}^{\circ}, \phi_{2}\right), \\
x_{1}(0)=x_{1}^{0} \text { and } x_{2}(0)=x_{2}^{0},
\end{array}\right.
$$


with $\mathbf{x}(t)=\left(x_{1}(t), x_{2}(t)\right)$ and $\mathbf{u}(t)=\left(u_{1}(t), u_{2}(t)\right)$, where $S\left(K_{1}, g_{1}, J_{1}^{\circ}, \phi_{1}\right) \times S\left(K_{2}, g_{2}, J_{2}^{\circ}, \phi_{2}\right)$ stands for the solution set of the system of hemivariational inequalities ((SHVI), for short): find $\left(u_{1}(t), u_{2}(t)\right):[0, T] \rightarrow$ $\mathrm{K}_{1} \times \mathrm{K}_{2}$ such that

$$
\left\{\begin{array}{l}
\left\langle g_{1}\left(t, x_{1}(t), x_{2}(t), u_{1}(t)\right), v_{1}-u_{1}(t)\right\rangle_{u_{1}^{*} \times u_{1}}+J_{1}^{\circ}\left(u_{1}(t), u_{2}(t) ; v_{1}-u_{1}(t)\right) \\
\quad+\phi_{1}\left(v_{1}\right)-\phi_{1}\left(u_{1}(t)\right) \geqslant 0, \forall v_{1} \in K_{1} \\
\quad\left\langle g_{2}\left(t, x_{1}(t), x_{2}(t), u_{2}(t)\right), v_{2}-u_{2}(t)\right\rangle u_{2}^{*} \times u_{2}+J_{2}^{\circ}\left(u_{1}(t), u_{2}(t) ; v_{2}-u_{2}(t)\right) \\
\quad+\phi_{2}\left(v_{2}\right)-\phi_{2}\left(u_{2}(t)\right) \geqslant 0, \forall v_{2} \in K_{2} .
\end{array}\right.
$$

Here, for $i=1,2, V=V_{1} \times V_{2}$ and $U=U_{1} \times U_{2}$ with $V_{i}$ and $U_{i}$ being real Banach spaces, $K_{i}$ is a convex subset of $U_{i}, A_{i}: D\left(A_{i}\right) \subseteq V_{i} \rightarrow V_{i}$ is the infinitesimal generator of a $C_{0}$-semigroup $e^{A_{i} t}$ in $V_{i}$, $\phi_{i}: \mathrm{U}_{i} \rightarrow \mathbf{R} \cup\{+\infty\}$ is a proper, convex, and lower semicontinuous functional, and $f_{i}:[0, T] \times V \times U \rightarrow V_{i}$ and $g_{i}:[0, T] \times V_{1} \times V_{2} \times K_{i} \rightarrow U_{i}^{*}$ are fixed mappings. For $i, j=1,2$ and $i \neq j$, the notation $J_{i}^{\circ}\left(u_{1}, u_{2} ; v_{i}\right)$ stands for the partial generalized Clark directional derivative ([28]) of a locally Lipschitz function $\mathrm{J}: \mathrm{U}=$ $\mathrm{U}_{1} \times \mathrm{U}_{2} \rightarrow \mathbf{R}$ with respect to the $i$ th variable at the point $\mathrm{u}_{\mathrm{i}} \in \mathrm{U}_{i}$ in the direction $v_{i} \in \mathrm{U}_{i}$ for the given $u_{j} \in u_{j}$.

The solutions of problem (SEESHVI) are understood in the following mild sense.

Definition 1.2. A pair of functions $(\mathbf{x}, \mathbf{u})$, with $\mathbf{x}=\left(\mathrm{x}_{1}, \mathrm{x}_{2}\right) \in \mathrm{C}([0, \mathrm{~T}] ; \mathrm{V})$ and $\mathbf{u}=\left(\mathrm{u}_{1}, \mathrm{u}_{2}\right):[0, \mathrm{~T}] \rightarrow \mathrm{K}_{1} \times \mathrm{K}_{2}$ measurable, is said to be a mild solution of problem (SEESHVI) if

$$
\left\{\begin{array}{l}
x_{1}(t)=e^{A_{1} t} x_{1}^{0}+\int_{0}^{t} e^{A_{1}(t-s)} f_{1}(s, x(s), u(s)) d s, t \in[0, T], \\
x_{2}(t)=e^{A_{2} t} x_{2}^{0}+\int_{0}^{t} e^{A_{2}(t-s)} f_{2}(s, x(s), u(s)) d s, t \in[0, T],
\end{array}\right.
$$

and $\mathbf{u}(s) \in S\left(K_{1}, g_{1}, J_{1}^{\circ}, \phi_{1}\right) \times S\left(K_{2}, g_{2}, J_{2}^{\circ}, \phi_{2}\right), s \in[0, T]$. If $(\mathbf{x}, \mathbf{u})$ is a mild solution of problem (SEESHVI), then $\mathbf{x}$ is called the mild trajectory and $\mathbf{u}$ the variational control trajectory.

The purpose of the present paper is to investigate the properties of the solution set for the general problem (SEESHVI). The main point is that (SEESHVI) is described by a system of partial differential equations (1.1), with $A_{i}$ for example the Laplace operator, subject to an infinite-dimensional system of hemivariational inequalities (1.2). This incorporates large classes of problems and models and here we extend the previous works dealing with such type of problems.

First, we prove the essential properties as the superpositional measurability and upper semicontinuity for the solution set of a general system of hemivariational inequalities. Then we establish our main result stating that the solution set of problem (SEESHVI) is nonempty and compact. In our approach we make use of various analytical and topological tools such as the properties of generalized directional derivative (in the sense of Clarke), KKM theorem, monotonicity, theory of semigroups, measure of noncompactness, Filippov implicit function lemma and fixed-point theory for set-valued mappings.

The paper is structured as follows. Section 2 contains basic definitions and preliminary facts needed in the sequel. Section 3 presents a general existence theorem for the system of hemivariational inequalities related to problem (SEESHVI). It also studies the upper semicontinuity, superpositional measurability, compactness, and convexity properties of the solution set. Section 4 focuses on the existence and qualitative properties of the solution set for problem (SEESHVI).

\section{Preliminaries}

In this section, we first recall some prerequisites regarding set-valued mappings that will be used later on. More information can be found in $[12,20,34]$.

For any nonempty set $\mathrm{Y}$, we denote by $\mathrm{P}(\mathrm{Y})$ the collection of its nonempty subsets. For easy reference, we also introduce $\mathrm{K}(\mathrm{Y}):=\{\mathrm{D} \in \mathrm{P}(\mathrm{Y}): \mathrm{D}$ is compact $\}$ and $\mathrm{K} v(\mathrm{Y}):=\{\mathrm{D} \in \mathrm{P}(\mathrm{Y}): \mathrm{D}$ is compact and convex $\}$.

We first recall a useful classical result. 
Lemma 2.1 ([6]). Let $\mathrm{K}$ be a nonempty subset of a Hausdorff topological vector space $\mathrm{E}_{1}$ and let $\mathrm{G}: \mathrm{K} \rightarrow \mathrm{P}\left(\mathrm{E}_{1}\right)$ be a set-valued mapping with the properties:

(a) $\mathrm{G}$ is a KKM mapping, that is, for any $\left\{v_{1}, v_{2}, \cdots, v_{n}\right\} \subset \mathrm{K}$, one has that its convex hull $\operatorname{co}\left\{v_{1}, v_{2}, \cdots, v_{n}\right\}$ is contained in $\bigcup_{i=1}^{n} \mathrm{G}\left(v_{i}\right)$;

(b) $\mathrm{G}(v)$ is closed in $\mathrm{E}_{1}$ for every $v \in \mathrm{K}$;

(c) $\mathrm{G}\left(v_{0}\right)$ is compact in $\mathrm{E}_{1}$ for some $v_{0} \in \mathrm{K}$.

Then it holds $\bigcap_{v \in \mathrm{K}} \mathrm{G}(v) \neq \emptyset$.

Let us mention a few facts about the measurability of set-valued mappings.

Definition 2.2. Let $E$ and $E_{1}$ be Banach spaces and let an interval $I \subset \mathbf{R}$. We say that $F: I \times E \rightarrow P\left(E_{1}\right)$ is superpositionally measurable if, for every measurable set-valued mapping $Q: I \rightarrow K(E)$, the composition $\Phi: \mathrm{I} \rightarrow \mathrm{P}\left(\mathrm{E}_{1}\right)$ given by $\Phi(\mathrm{t})=\mathrm{F}(\mathrm{t}, \mathrm{Q}(\mathrm{t}))$ is measurable.

Theorem 2.3 ([34]). If $\mathrm{F}: \mathrm{I} \times \mathrm{E} \rightarrow \mathrm{K}\left(\mathrm{E}_{1}\right)$ satisfies the Caratheodory condition or $\mathrm{F}$ is upper or lower semicontinuous, then $\mathrm{F}$ is superpositionally measurable.

We also cite from [12, Theorem 1.3.5] a sufficient condition for getting strongly measurable selections. In the following we fix a number $0<\mathrm{T}<\infty$.

Theorem 2.4. Let $\mathrm{E}$ and $\mathrm{E}_{1}$ be Banach spaces. Assume that the set-valued mapping $\mathrm{G}:[0, \mathrm{~T}] \times \mathrm{E} \rightarrow \mathrm{K}\left(\mathrm{E}_{1}\right)$ satisfies:

(a) for every $\mathrm{x} \in \mathrm{E}, \mathrm{G}(\cdot, \mathrm{x}):[0, \mathrm{~T}] \rightarrow \mathrm{K}\left(\mathrm{E}_{1}\right)$ has a strongly measurable selection;

(b) for a.e. $\mathrm{t} \in[0, \mathrm{~T}], \mathrm{G}(\mathrm{t}, \cdot): \mathrm{E} \rightarrow \mathrm{K}\left(\mathrm{E}_{1}\right)$ is upper semicontinuous.

Then, for every strongly measurable function $\mathrm{q}:[0, \mathrm{~T}] \rightarrow \mathrm{E}$, there exists a strongly measurable selection $\mathrm{g}:[0, \mathrm{~T}] \rightarrow$ $E_{1}$ of the composition $M:[0, T] \rightarrow K\left(E_{1}\right), M(t)=G(t, q(t))$ for a.e. $t \in[0, T]$.

Now we briefly focus on the important notion of measure of noncompactness.

Definition 2.5. Let $E$ be a Banach space and let $(\mho, \leqslant)$ be a partially ordered set. A mapping $\beta: P(E) \rightarrow \mho$ is called a measure of noncompactness (MNC, for short) in $E$ if $\beta(\overline{\mathrm{CO}} \Omega)=\beta(\Omega)$ for every $\Omega \in P(E)$.

An important example is the Hausdorff MNC $\chi$ defined by means of diameters of sets:

$$
\chi(\Omega):=\inf \left\{\epsilon>0: \exists \Omega_{i} \in P(E) \text { with } \operatorname{diam}\left(\Omega_{i}\right) \leqslant \epsilon, i=1, \ldots, n \text {, and } \Omega \subseteq \bigcup_{i=1}^{n} \Omega_{i}\right\} .
$$

We also need the monotone nonsingular $\mathrm{MNC}$ in the space $\mathrm{C}([0, \mathrm{~T}] ; \mathrm{E})$ as introduced in $[12$, Example 2.1.4]. Namely, fixing a constant $L>0$, for each nonempty bounded set $\Omega \subset C([0, T]$; $E)$ it is equal to

$$
v(\Omega):=\max _{\omega \in \Delta(\Omega)}\left(\gamma(\omega), \bmod _{C}(\omega)\right),
$$

where $\Delta(\Omega)$ denotes the collection of all countable subsets of $\Omega$, while

$$
\gamma(\omega):=\sup _{t \in[0, T]} e^{-L t} \chi(\omega(t)), \bmod _{C}(\omega):=\lim _{\delta \rightarrow 0} \sup _{\chi \in \omega} \max _{\left|t_{1}-t_{2}\right| \leqslant \delta}\left\|x\left(t_{1}\right)-x\left(t_{2}\right)\right\|_{E} .
$$

In (2.1) the maximum is taken in the sense of the order on $\mho=\mathbf{R}^{2}$.

Let $\beta_{1}$ and $\beta_{2}$ be real MNCs (that is, $\left.\mho=[0,+\infty]\right)$ in $E_{1}$ and $E_{2}$, respectively. For any $k \geqslant 0, F: X \subset$ $E_{1} \rightarrow K\left(E_{2}\right)$ is said to be $\left(k, \beta_{1}, \beta_{2}\right)$-bounded if

$$
\beta_{2}(F(\Omega)) \leqslant k \beta_{1}(\Omega) \text { for all } \Omega \subseteq X .
$$

The following criterion of $\left(k, \beta_{1}, \beta_{2}\right)$-boundedness is taken from [12, Proposition 2.2.2]. 
Theorem 2.6. Let $\chi_{1}$ and $\chi_{2}$ be the Hausdorff MNCs in $\mathrm{E}_{1}$ and $\mathrm{E}_{2}$, respectively. Suppose that $\mathrm{X} \subset \mathrm{E}_{1}$ and $\mathrm{F}: \mathrm{X} \times \mathrm{E}_{1} \rightarrow \mathrm{K}\left(\mathrm{E}_{2}\right)$ satisfy the conditions:

(1) there exists $k \in \mathbf{R}^{+}$such that for every $x \in X, F(x, \cdot): E_{1} \rightarrow K\left(E_{2}\right)$ is $k$-Lipschitz with respect to the Hausdorff metric $\mathcal{H}$ on $\mathrm{K}\left(\mathrm{E}_{2}\right)$, that is,

$$
\mathcal{H}\left(F\left(x, y_{1}\right), F\left(x, y_{2}\right)\right) \leqslant k\left\|y_{1},-y_{2}\right\|, \forall y_{1}, y_{2} \in E_{1} ;
$$

(2) the set $\mathrm{F}(\Omega \times\{\mathrm{y}\})$ is relatively compact in $\mathrm{E}_{2}$ for every bounded subset $\Omega \subset \mathrm{X}$ and $\mathrm{y} \in \mathrm{E}_{1}$.

Then $\mathrm{G}: \mathrm{X} \rightarrow \mathrm{K}\left(\mathrm{E}_{2}\right)$ defined as $\mathrm{G}(\mathrm{x})=\mathrm{F}(\mathrm{x}, \mathrm{x})$ is $\left(\mathrm{k}, \mathrm{x}_{1}, \mathrm{x}_{2}\right)$-bounded.

Further, we turn to the set-valued fixed point theory by listing from [12] some basic statements.

Definition 2.7. Let $X$ be a closed subset of a Banach space $E$ and let $\beta$ be a real MNC in $E$. A set-valued mapping $F: X \rightarrow K(E)$ is said to be $\beta$-condensing if there is some $0 \leqslant k<1$ such that $\beta(F(\Omega)) \leqslant k \beta(\Omega)$ for every $\Omega \in \mathrm{P}(\mathrm{X})$.

Theorem 2.8. If $\mathrm{M}$ is a nonempty closed convex subset of a Banach space $\mathrm{E}$ and $\mathrm{F}: \mathrm{M} \rightarrow \mathrm{K} v(\mathrm{M})$ be a closed $\beta$-condensing set-valued mapping, with a nonsingular MNC $\beta$ in $\mathrm{E}$, then the set $\operatorname{Fix}(\mathrm{F})$ of fixed points of $\mathrm{F}$ is nonempty.

Theorem 2.9. Let $\mathrm{C}$ be a closed subset of a Banach space $\mathrm{E}$ and let $\mathrm{F}: \mathrm{C} \rightarrow \mathrm{K}(\mathrm{E})$ be a closed set-valued mapping, which is $\beta$-condensing on every bounded subset of $\mathrm{C}$, with a monotone MNC $\beta$ in $\mathrm{E}$. If Fix $(\mathrm{F})$ is bounded, then it is compact.

In what follows, let us proceed to the definition of the generalized gradient of Clarke for a locally Lipschitzian functional $h: E \rightarrow \mathbf{R}$ ([20]), we denote by $h^{\circ}(u ; v)$ the Clarke generalized directional derivative of $h$ at $u$ in the direction $v$, that is,

$$
h^{\circ}(u ; v):=\limsup _{\lambda \rightarrow 0^{+}, y \rightarrow u} \frac{h(y+\lambda v)-h(y)}{\lambda} .
$$

Recall also that the generalized Clarke subdifferential of $h$ at $u$, denoted by $\partial h(u)$, is a subset of $E^{*}$ given by

$$
\partial h(u):=\left\{u^{*} \in E^{*}: h^{\circ}(u ; v) \geqslant\left\langle u^{*}, v\right\rangle_{E^{*} \times E}, \forall v \in E\right\} .
$$

The following lemma provides some basic properties for the Clarke's generalized directional derivative and the Clarke's generalized gradient; see e.g., [20, 28, 30].

Lemma 2.10. Let $\mathrm{h}: \mathrm{E} \rightarrow \mathbf{R}$ be a locally Lipschitz functional on $\mathrm{E}$ and let $\mathrm{u}, v \in \mathrm{E}$ be two given elements. Then

(i) the function $v \mapsto \mathrm{h}^{\circ}(\mathrm{u} ; v)$ is finite, positively homogeneous, subadditive and thus convex on $\mathrm{E}$;

(ii) $h^{\circ}(u ; v)$ is upper semicontinuous on $\mathrm{E} \times \mathrm{E}$ as a function of $(u, v)$, as a function of $v$ alone, is Lipschitz continuous on $\mathrm{E}$;

(iii) $h^{\circ}(u ;-v)=(-h)^{\circ}(u ; v)$;

(iv) for all $\mathrm{u} \in \mathrm{E}, \partial \mathrm{h}(\mathrm{u})$ is a nonempty, convex, bounded, and weak*-compact subset of $\mathrm{E}^{*}$;

(v) for all $v \in \mathrm{E}$, one has $\mathrm{h}^{\circ}(\mathrm{u} ; v)=\max \left\{\langle\xi, v\rangle_{\mathrm{E}^{*} \times \mathrm{E}}: \xi \in \partial \mathrm{h}(\mathrm{u})\right\}$;

(vi) the graph of the Clarke's generalized gradient $\partial \mathrm{h}(\mathrm{u})$ is closed in $\mathrm{E} \times\left(w^{*}-\mathrm{E}^{*}\right)$ topology, where ( $\left.w^{*}-\mathrm{E}^{*}\right)$ denotes the space $\mathrm{E}^{*}$ equipped with weak $k^{*}$ topology, i.e., if $\left\{\mathrm{u}_{\mathrm{n}}\right\} \subset \mathrm{E}$ and $\left\{\mathrm{u}_{\mathrm{n}}^{*}\right\} \subset \mathrm{E}^{*}$ are sequences such that $\mathrm{u}_{\mathrm{n}}^{*} \in$ $\partial \mathrm{h}\left(\mathrm{u}_{\mathrm{n}}\right), \mathrm{u}_{\mathrm{n}} \rightarrow \mathrm{u}$ in $\mathrm{E}$ and $\mathrm{u}_{\mathrm{n}}^{*} \rightarrow \mathrm{u}^{*}$ weak $\mathrm{k}^{*}$ in in $\mathrm{E}^{*}$, then $\mathrm{u}^{*} \in \partial \mathrm{h}(\mathrm{u})$.

Lemma 2.11 ([28, Lemma 3.6]). Let $\mathrm{U}=\mathrm{U}_{1} \times \mathrm{U}_{2}$ be endowed by the norm $\|\mathbf{u}\| \mathrm{u}=\left\|\mathrm{u}_{1}\right\| \mathrm{u}_{1}+\left\|\mathrm{u}_{2}\right\| \mathrm{u}_{2}, \forall \mathbf{u}=$ $\left(\mathrm{u}_{1}, \mathrm{u}_{2}\right) \in \mathrm{U}$. Suppose that $\mathrm{J}: \mathrm{U}=\mathrm{U}_{1} \times \mathrm{U}_{2} \rightarrow \mathbf{R}$ is a local Lipschitz functional such that $\mathrm{J}\left(\mathrm{u}_{1}, \mathrm{u}_{2}\right)+\mathrm{J}\left(v_{1}, v_{2}\right)=$ $\mathrm{J}\left(\mathrm{u}_{1}, v_{2}\right)+\mathrm{J}\left(v_{1}, \mathrm{u}_{2}\right)$ for all $\left(\mathrm{u}_{1}, \mathrm{u}_{2}\right),\left(v_{1}, v_{2}\right) \in \mathrm{U}_{1} \times \mathrm{U}_{2}$. Then, for any sequence $\mathbf{u}^{\mathrm{n}}=\left(\mathrm{u}_{1}^{\mathfrak{n}}, \mathrm{u}_{2}^{\mathfrak{n}}\right) \in \mathrm{U}$ converging strongly to $\mathbf{u}=\left(\mathrm{u}_{1}, \mathrm{u}_{2}\right) \in \mathrm{U}$ and $v_{i}^{n} \in \mathrm{U}_{i}$ converging strongly to $v_{i} \in \mathrm{U}_{i}$, one has

$$
\limsup _{n \rightarrow \infty} J_{i}^{\circ}\left(u_{1}^{n}, u_{2}^{n} ; v_{i}^{n}\right) \leqslant J_{i}^{\circ}\left(u_{1}, u_{2} ; v_{i}\right), i=1,2 .
$$


At the end of this section, we give a theorem from [8], which is important to the proof of our main results.

Theorem 2.12 ([8]). Let $\mathrm{C} \subset \mathrm{E}$ be nonempty, closed, and convex, $\mathrm{C}^{*} \subset \mathrm{E}^{*}$ be nonempty, closed, convex, and bounded, $\varphi: E \rightarrow \mathbf{R}$ be proper, convex and lower semicontinuous and $\mathrm{y} \in \mathrm{C}$ be arbitrary. Assume that, for each $x \in C$, there exists $x^{*}(x) \in C^{*}$ such that $\left\langle x^{*}(x), x-y\right\rangle^{*} \times E \geqslant \varphi(y)-\varphi(x)$. Then, there exists $\mathrm{y}^{*} \in \mathrm{C}^{*}$ such that $\left\langle y^{*}, x-y\right\rangle_{E^{*} \times E} \geqslant \varphi(y)-\varphi(x), \forall x \in C$.

\section{Properties of solution set for SHVI}

Let $\mathrm{U}=\mathrm{U}_{1} \times \mathrm{U}_{2}$, where $\mathrm{U}_{1}$ and $\mathrm{U}_{2}$ are real reflexive Banach spaces, endowed with the norm defined by $\|\mathbf{u}\| \mathrm{u}:=\left\|\mathrm{u}_{1}\right\| \mathrm{u}_{1}+\left\|\mathrm{u}_{2}\right\|_{\mathrm{u}_{2}}$ for all $\mathbf{u}=\left(\mathrm{u}_{1}, \mathrm{u}_{2}\right) \in \mathrm{U}$, where $\mathrm{U}$ is a reflexive Banach space ([34]). Let $J: \mathrm{U} \rightarrow \mathbf{R}$ be a locally Lipschitz functional on $U$. Given a nonempty subset $K_{i} \subseteq U_{i}$, a mapping $Q_{i}: K_{i} \rightarrow U_{i}^{*}$ and a proper function $\phi_{i}: U_{i} \rightarrow \mathbf{R} \cup\{+\infty\}$ for $i=1,2$, we consider the following system of hemivariational inequalities ((SHVI), for short): find $\mathbf{u}=\left(\mathrm{u}_{1}, \mathrm{u}_{2}\right) \in \mathrm{K}_{1} \times \mathrm{K}_{2}$ such that

$$
\left\{\begin{array}{l}
\left\langle\mathrm{Q}_{1}\left(\mathrm{u}_{1}\right), v_{1}-\mathrm{u}_{1}\right\rangle \mathrm{u}_{1}^{*} \times \mathrm{u}_{1}+\mathrm{J}_{1}^{\circ}\left(\mathrm{u}_{1}, \mathrm{u}_{2} ; v_{1}-\mathrm{u}_{1}\right)+\phi_{1}\left(v_{1}\right)-\phi_{1}\left(\mathrm{u}_{1}\right) \geqslant 0, \forall v_{1} \in \mathrm{K}_{1}, \\
\left\langle\mathrm{Q}_{2}\left(\mathrm{u}_{2}\right), v_{2}-\mathrm{u}_{2}\right\rangle \mathrm{u}_{2}^{*} \times \mathrm{u}_{2}+\mathrm{J}_{2}^{\circ}\left(\mathrm{u}_{1}, \mathrm{u}_{2} ; v_{2}-\mathrm{u}_{2}\right)+\phi_{2}\left(v_{2}\right)-\phi_{2}\left(\mathrm{u}_{2}\right) \geqslant 0, \forall v_{2} \in \mathrm{K}_{2} .
\end{array}\right.
$$

Our first main result of this section is as follows.

Theorem 3.1. Let $\mathrm{J}: \mathrm{U} \rightarrow \mathbf{R}$ be a locally Lipschitz functional on $\mathrm{U}=\mathrm{U}_{1} \times \mathrm{U}_{2}$. Let $\mathrm{K}_{\mathrm{i}}$ be a nonempty closed convex subset of $u_{i}$ for $i=1,2$. Assume that for $i=1,2$,

(i) $\mathrm{Q}_{i}: \mathrm{K}_{i} \rightarrow \mathrm{U}_{i}^{*}$ is monotone on $\mathrm{K}_{i}$, i.e., $\left\langle\mathrm{Q}_{i}\left(v_{i}\right)-\mathrm{Q}_{i}\left(\mathrm{u}_{\mathrm{i}}\right), v_{i}-\mathrm{u}_{i}\right\rangle_{\mathrm{u}_{i}^{*} \times \mathrm{u}_{i}} \geqslant 0, \forall \mathrm{u}_{i}, v_{i} \in \mathrm{K}_{i}$, and satisfies

$$
\limsup _{\lambda \rightarrow 0^{+}}\left\langle Q_{i}\left(\lambda u_{i}+(1-\lambda) v_{i}\right), v_{i}-u_{i}\right\rangle u_{i}^{*} \times u_{i} \leqslant\left\langle Q_{i}\left(v_{i}\right), v_{i}-u_{i}\right\rangle u_{i}^{*} \times u_{i}, \forall u_{i}, v_{i} \in K_{i}
$$

(ii) $\phi_{i}: \mathrm{U}_{i} \rightarrow \mathbf{R} \cup\{+\infty\}$ is a proper, convex, and lower semicontinuous function;

(iii) $\mathrm{J}\left(\mathrm{u}_{1}, \mathrm{u}_{2}\right)+\mathrm{J}\left(v_{1}, v_{2}\right)=\mathrm{J}\left(\mathrm{u}_{1}, v_{2}\right)+\mathrm{J}\left(v_{1}, \mathrm{u}_{2}\right)$ for all $\mathbf{u}=\left(\mathrm{u}_{1}, \mathrm{u}_{2}\right), \mathbf{v}=\left(v_{1}, v_{2}\right)$ in $\mathrm{u}$;

(iv) $\partial_{i} \mathrm{~J}: \mathrm{U} \rightarrow 2^{\mathrm{U}_{i}^{*}}$ is monotone on $\mathrm{U}$, i.e.,

$$
\left\langle\zeta_{i}-\xi_{i}, \nu_{i}-u_{i}\right\rangle u_{i}^{*} \times u_{i} \geqslant 0, \forall(\mathbf{u}, \mathbf{v}) \in U \times U, \forall\left(\xi_{i}, \zeta_{i}\right) \in \partial_{i} J(\mathbf{u}) \times \partial_{i} J(\mathbf{v})
$$

(v) if the set $\mathrm{K}_{i}$ is unbounded in $\mathrm{U}_{i}$, there exist $\left(\mathrm{u}_{1}^{0}, \mathrm{u}_{2}^{0}\right) \in \mathrm{K}_{1} \times \mathrm{K}_{2}$ and positive number $\mathrm{r}>0$ such that one of the following inequalities holds:

$$
\left\{\begin{array}{l}
\left\langle\mathrm{Q}_{1}\left(v_{1}\right), \mathrm{u}_{1}^{0}-v_{1}\right\rangle \mathrm{u}_{1}^{*} \times \mathrm{u}_{1}+\mathrm{J}_{1}^{\circ}\left(\mathrm{u}_{1}^{0}, \mathrm{u}_{2}^{0} ; \mathrm{u}_{1}^{0}-v_{1}\right)+\phi_{1}\left(\mathrm{u}_{1}^{0}\right)-\phi_{1}\left(v_{1}\right)<0, \\
\left\langle\mathrm{Q}_{2}\left(v_{2}\right), \mathrm{u}_{2}^{0}-v_{2}\right\rangle \mathrm{u}_{2}^{*} \times \mathrm{u}_{2}+\mathrm{J}_{2}^{\circ}\left(\mathrm{u}_{1}^{0}, \mathrm{u}_{2}^{0} ; \mathrm{u}_{2}^{0}-v_{2}\right)+\phi_{2}\left(\mathrm{u}_{2}^{0}\right)-\phi_{2}\left(v_{2}\right)<0,
\end{array}\right.
$$

for all $\left(v_{1}, v_{2}\right) \in \mathrm{K}_{1} \times \mathrm{K}_{2}$ with $\max _{\mathrm{i} \in\{1,2\}}\left\|v_{i}\right\| \mathrm{u}_{\mathrm{i}}>\mathrm{r}$.

Then $\mathbf{u}=\left(\mathrm{u}_{1}, \mathrm{u}_{2}\right) \in \mathrm{K}_{1} \times \mathrm{K}_{2}$ is a solution of (SHVI) if and only if it is a solution to the following system of generalized mixed variational inequalities (SGMVI): find $\mathbf{u}=\left(\mathrm{u}_{1}, \mathrm{u}_{2}\right) \in \mathrm{K}_{1} \times \mathrm{K}_{2}$ such that, for all $\mathbf{v}=\left(v_{1}, v_{2}\right) \in$ $\mathrm{K}_{1} \times \mathrm{K}_{2}$, there exists $\left(\xi_{1}, \xi_{2}\right) \in \partial_{1} \mathrm{~J}\left(v_{1}, v_{2}\right) \times \partial_{2} \mathrm{~J}\left(v_{1}, v_{2}\right)$ satisfying

$$
\left\{\begin{array}{l}
\left\langle\mathrm{Q}_{1}\left(v_{1}\right)+\xi_{1}, v_{1}-\mathrm{u}_{1}\right\rangle \mathrm{u}_{1}^{*} \times \mathrm{u}_{1}+\phi_{1}\left(v_{1}\right)-\phi_{1}\left(\mathrm{u}_{1}\right) \geqslant 0 \\
\left\langle\mathrm{Q}_{2}\left(v_{2}\right)+\xi_{2}, v_{2}-\mathrm{u}_{2}\right\rangle \mathrm{u}_{2}^{*} \times \mathrm{u}_{2}+\phi_{2}\left(v_{2}\right)-\phi_{2}\left(\mathrm{u}_{2}\right) \geqslant 0
\end{array}\right.
$$

Moreover, the solution set of (SHVI) is nonempty, convex, and closed in $\mathrm{U}=\mathrm{U}_{1} \times \mathrm{U}_{2}$. 
Proof. Firstly, we claim that $\mathbf{u}=\left(\mathrm{u}_{1}, \mathrm{u}_{2}\right) \in \mathrm{K}_{1} \times \mathrm{K}_{2}$ is a solution of (SHVI) if and only if $\mathbf{u}=\left(\mathrm{u}_{1}, \mathrm{u}_{2}\right)$ solves

$$
\left\{\begin{array}{l}
\left\langle\mathrm{Q}_{1}\left(v_{1}\right), v_{1}-\mathrm{u}_{1}\right\rangle \mathrm{u}_{1}^{*} \times \mathrm{u}_{1}+\mathrm{J}_{1}^{\circ}\left(v_{1}, v_{2} ; v_{1}-\mathrm{u}_{1}\right)+\phi_{1}\left(v_{1}\right)-\phi_{1}\left(\mathrm{u}_{1}\right) \geqslant 0, \forall v_{1} \in \mathrm{K}_{1}, \\
\left\langle\mathrm{Q}_{2}\left(v_{2}\right), v_{2}-\mathrm{u}_{2}\right\rangle \mathrm{u}_{2}^{*} \times \mathrm{u}_{2}+\mathrm{J}_{2}^{\circ}\left(v_{1}, v_{2} ; v_{2}-\mathrm{u}_{2}\right)+\phi_{2}\left(v_{2}\right)-\phi_{2}\left(\mathrm{u}_{2}\right) \geqslant 0, \forall v_{2} \in \mathrm{K}_{2} .
\end{array}\right.
$$

Indeed, if $\mathbf{u}=\left(\mathrm{u}_{1}, \mathrm{u}_{2}\right) \in \mathrm{K}_{1} \times \mathrm{K}_{2}$ is a solution of (SHVI), then we have

$$
\left\{\begin{array}{l}
\left\langle\mathrm{Q}_{1}\left(\mathrm{u}_{1}\right), v_{1}-\mathrm{u}_{1}\right\rangle \mathrm{u}_{1}^{*} \times \mathrm{u}_{1}+\mathrm{J}_{1}^{\circ}\left(\mathrm{u}_{1}, \mathrm{u}_{2} ; v_{1}-\mathrm{u}_{1}\right)+\phi_{1}\left(v_{1}\right)-\phi_{1}\left(\mathrm{u}_{1}\right) \geqslant 0, \forall v_{1} \in \mathrm{K}_{1}, \\
\left\langle\mathrm{Q}_{2}\left(\mathrm{u}_{2}\right), v_{2}-\mathrm{u}_{2}\right\rangle \mathrm{u}_{2}^{*} \times \mathrm{u}_{2}+\mathrm{J}_{2}^{\circ}\left(\mathrm{u}_{1}, \mathrm{u}_{2} ; v_{2}-\mathrm{u}_{2}\right)+\phi_{2}\left(v_{2}\right)-\phi_{2}\left(\mathrm{u}_{2}\right) \geqslant 0, \forall v_{2} \in \mathrm{K}_{2} .
\end{array}\right.
$$

Let $\mathbf{v}=\left(v_{1}, v_{2}\right) \in K_{1} \times K_{2}$. For $i=1,2$, by Lemma $2.10(v)$ we know that there exist $\xi_{i} \in \partial_{i} J\left(u_{1}, u_{2}\right)$ and $\zeta_{i} \in \partial_{i} J\left(v_{1}, v_{2}\right)$ such that

$$
J_{i}^{\circ}\left(u_{1}, u_{2} ; v_{i}-u_{i}\right)=\left\langle\xi_{i}, v_{i}-u_{i}\right\rangle u_{i}^{*} \times u_{i} \text { and } J_{i}^{\circ}\left(v_{1}, v_{2} ; v_{i}-u_{i}\right)=\left\langle\zeta_{i}, v_{i}-u_{i}\right\rangle_{u_{i}^{*} \times u_{i}} .
$$

For $i=1,2$, since $\partial_{i} J: U \rightarrow 2^{U_{i}^{*}}$ is monotone, we have

$$
J_{i}^{\circ}\left(v_{1}, v_{2} ; v_{i}-u_{i}\right)-J_{i}^{\circ}\left(u_{1}, u_{2} ; v_{i}-u_{i}\right)=\left\langle\zeta_{i}-\xi_{i}, v_{i}-u_{i}\right\rangle u_{i}^{*} \times u_{i} \geqslant 0,
$$

which hence yields

$$
\mathrm{J}_{i}^{\circ}\left(v_{1}, v_{2} ; v_{i}-u_{i}\right) \geqslant J_{i}^{\circ}\left(u_{1}, u_{2} ; v_{i}-u_{i}\right) .
$$

So, it follows from the monotonicity of $Q_{i}, i=1,2$ in assumption (i) that $\mathbf{u}=\left(u_{1}, u_{2}\right)$ is also a solution of (3.1). Conversely, assume that $\mathbf{u}=\left(\mathrm{u}_{1}, \mathrm{u}_{2}\right) \in \mathrm{K}_{1} \times \mathrm{K}_{2}$ is a solution of (3.1). Since the set $\mathrm{K}_{i}$ is convex for $i=1,2$, it follows that $u_{i, \lambda}:=\lambda v_{i}+(1-\lambda) u_{i} \in K_{i}$ for all $\lambda \in(0,1)$ and all $v_{i} \in K_{i}$, and hence

$$
\left\{\begin{array}{l}
\left\langle Q_{1}\left(u_{1, \lambda}\right), u_{1, \lambda}-u_{1}\right\rangle u_{1}^{*} \times u_{1}+J_{1}^{\circ}\left(u_{1, \lambda}, u_{2, \lambda} ; u_{1, \lambda}-u_{1}\right)+\phi_{1}\left(u_{1, \lambda}\right)-\phi_{1}\left(u_{1}\right) \geqslant 0, \\
\left\langle Q_{2}\left(u_{2, \lambda}\right), u_{2, \lambda}-u_{2}\right\rangle u_{2}^{*} \times u_{2}+J_{2}^{\circ}\left(u_{1, \lambda}, u_{2, \lambda} ; u_{2, \lambda}-u_{2}\right)+\phi_{2}\left(u_{2, \lambda}\right)-\phi_{2}\left(u_{2}\right) \geqslant 0 .
\end{array}\right.
$$

Then by assumption (ii) and the positive homogeneousness of the function $y_{i} \mapsto J_{i}^{\circ}\left(u_{1, \lambda}, u_{2, \lambda} ; y_{i}\right)$ (due to Lemma 2.10 (i)), there holds

$$
\left\{\begin{array}{l}
\left\langle\mathrm{Q}_{1}\left(\mathrm{u}_{1, \lambda}\right), v_{1}-\mathrm{u}_{1}\right\rangle \mathrm{u}_{1}^{*} \times \mathrm{u}_{1}+\mathrm{J}_{1}^{\circ}\left(\mathrm{u}_{1, \lambda}, \mathrm{u}_{2, \lambda} ; v_{1}-\mathrm{u}_{1}\right)+\phi_{1}\left(v_{1}\right)-\phi_{1}\left(\mathrm{u}_{1}\right) \geqslant 0, \\
\left\langle\mathrm{Q}_{2}\left(\mathrm{u}_{2, \lambda}\right), v_{2}-\mathrm{u}_{2}\right\rangle \mathrm{u}_{2}^{*} \times \mathrm{u}_{2}+\mathrm{J}_{2}^{\circ}\left(\mathrm{u}_{1, \lambda}, \mathrm{u}_{2, \lambda} ; v_{2}-\mathrm{u}_{2}\right)+\phi_{2}\left(v_{2}\right)-\phi_{2}\left(\mathrm{u}_{2}\right) \geqslant 0 .
\end{array}\right.
$$

For $i=1,2$, since $u_{i, \lambda} \rightarrow u_{i}$ strongly in $u_{i}$, by Lemma 3.6 of [28] we get

$$
\limsup _{\lambda \rightarrow 0} J_{i}^{\circ}\left(u_{1, \lambda}, u_{2, \lambda} ; v_{i}-u_{i}\right) \leqslant J_{i}^{\circ}\left(u_{1}, u_{2} ; v_{i}-u_{i}\right) .
$$

Passing to the limsup as $\lambda \rightarrow 0$ at both sides of the inequalities in (3.2) and making use of hypotheses (i) and (ii) imply that

$$
\left\{\begin{array}{l}
\left\langle\mathrm{Q}_{1}\left(\mathrm{u}_{1}\right), v_{1}-\mathrm{u}_{1}\right\rangle \mathrm{u}_{1}^{*} \times \mathrm{u}_{1}+\mathrm{J}_{1}^{\circ}\left(\mathrm{u}_{1}, \mathrm{u}_{2} ; v_{1}-\mathrm{u}_{1}\right)+\phi_{1}\left(v_{1}\right)-\phi_{1}\left(\mathrm{u}_{1}\right) \geqslant 0, \\
\left\langle\mathrm{Q}_{2}\left(\mathrm{u}_{2}\right), v_{2}-\mathrm{u}_{2}\right\rangle \mathrm{u}_{2}^{*} \times \mathrm{u}_{2}+\mathrm{J}_{2}^{\circ}\left(\mathrm{u}_{1}, \mathrm{u}_{2} ; v_{2}-\mathrm{u}_{2}\right)+\phi_{2}\left(v_{2}\right)-\phi_{2}\left(\mathrm{u}_{2}\right) \geqslant 0 .
\end{array}\right.
$$

Thus, $\mathbf{u}=\left(u_{1}, u_{2}\right) \in K_{1} \times K_{2}$ solves problem (SHVI), and hence the required equivalence is proven.

Secondly, we claim that $\mathbf{u}=\left(\mathfrak{u}_{1}, \mathfrak{u}_{2}\right) \in K_{1} \times K_{2}$ is a solution of problem (3.1) if and only if $\mathbf{u}=\left(u_{1}, u_{2}\right)$ solves problem (SGMVI).

Indeed, assume that $\mathbf{u}=\left(\mathrm{u}_{1}, \mathrm{u}_{2}\right) \in \mathrm{K}_{1} \times \mathrm{K}_{2}$ is a solution of problem (3.1). Let $\mathbf{v}=\left(v_{1}, v_{2}\right) \in \mathrm{K}_{1} \times \mathrm{K}_{2}$. By virtue of Lemma $2.10(\mathrm{v})$, one observes that

$$
\left\{\begin{array}{l}
\mathrm{J}_{1}^{\circ}\left(v_{1}, v_{2} ; v_{1}-\mathrm{u}_{1}\right)=\max \left\{\left\langle\xi_{1}, v_{1}-\mathrm{u}_{1}\right\rangle \mathrm{u}_{1}^{*} \times \mathrm{u}_{1}: \xi_{1} \in \partial_{1} \mathrm{~J}\left(v_{1}, v_{2}\right)\right\}, \\
\mathrm{J}_{2}^{\circ}\left(v_{1}, v_{2} ; v_{2}-\mathrm{u}_{2}\right)=\max \left\{\left\langle\xi_{2}, v_{2}-\mathrm{u}_{2}\right\rangle \mathrm{u}_{2}^{*} \times \mathrm{u}_{2}: \xi_{2} \in \partial_{2} \mathrm{~J}\left(v_{1}, v_{2}\right)\right\} .
\end{array}\right.
$$


Thus, it follows that for $i=1,2$, there exists $\xi_{i}\left(v_{1}, v_{2}, u_{i}\right) \in \partial_{i} J\left(v_{1}, v_{2}\right)$ such that

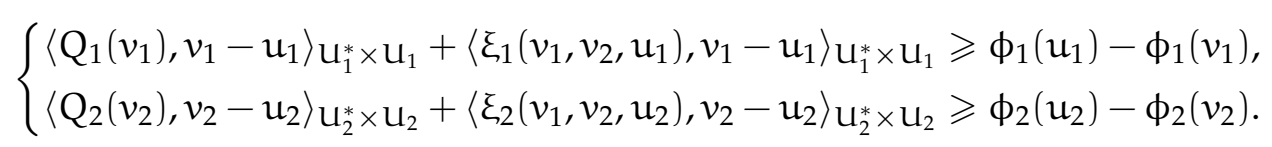

According to Lemma 2.10 (iv), $\partial_{1} J\left(v_{1}, v_{2}\right)$ and $\partial_{2} J\left(v_{1}, v_{2}\right)$ are nonempty, convex, bounded and closed subsets in $U_{1}^{*}$ and $U_{2}^{*}$, respectively. This implies that for $i=1,2$, the set $\left\{Q_{i}\left(v_{i}\right)+\xi_{i}: \xi_{i} \in \partial_{i} J\left(v_{1}, v_{2}\right)\right\}$ is also nonempty, convex, bounded, and closed in $U_{i}^{*}$. Therefore, for $i=1,2$, it follows from (3.3) and Theorem 2.12 with $\varphi_{i}(\cdot)=\phi_{i}(\cdot)$, which is proper, convex, and lower semicontinuous, that there exists a $\xi_{i} \in \partial_{i} J\left(v_{1}, v_{2}\right)$, which is independent on $u_{i}$, such that

$$
\left\{\begin{array}{l}
\left\langle\mathrm{Q}_{1}\left(v_{1}\right), v_{1}-\mathrm{u}_{1}\right\rangle \mathrm{u}_{1}^{*} \times \mathrm{u}_{1}+\left\langle\xi_{1}, v_{1}-\mathrm{u}_{1}\right\rangle \mathrm{u}_{1}^{*} \times \mathrm{u}_{1} \geqslant \phi_{1}\left(\mathrm{u}_{1}\right)-\phi_{1}\left(v_{1}\right), \\
\left\langle\mathrm{Q}_{2}\left(v_{2}\right), v_{2}-\mathrm{u}_{2}\right\rangle \mathrm{u}_{2}^{*} \times \mathrm{u}_{2}+\left\langle\xi_{2}, v_{2}-\mathrm{u}_{2}\right\rangle \mathrm{u}_{2}^{*} \times \mathrm{u}_{2} \geqslant \phi_{2}\left(\mathrm{u}_{2}\right)-\phi_{2}\left(v_{2}\right) .
\end{array}\right.
$$

Consequently, $\mathbf{u}=\left(\mathrm{u}_{1}, \mathrm{u}_{2}\right)$ is a solution of (SGMVI). Conversely, assume that $\mathbf{u}=\left(\mathrm{u}_{1}, \mathrm{u}_{2}\right) \in \mathrm{K}_{1} \times \mathrm{K}_{2}$ is a solution of (SGMVI), that is, for all $\mathbf{v}=\left(v_{1}, v_{2}\right) \in \mathrm{K}_{1} \times \mathrm{K}_{2}$, there exists $\left(\xi_{1}, \xi_{2}\right) \in \partial_{1} \mathrm{~J}\left(v_{1}, v_{2}\right) \times \partial_{2} \mathrm{~J}\left(v_{1}, v_{2}\right)$ satisfying

$$
\left\{\begin{array}{l}
\left\langle\mathrm{Q}_{1}\left(v_{1}\right)+\xi_{1}, v_{1}-\mathrm{u}_{1}\right\rangle \mathrm{u}_{1}^{*} \times \mathrm{u}_{1}+\phi_{1}\left(v_{1}\right)-\phi_{1}\left(\mathrm{u}_{1}\right) \geqslant 0 \\
\left\langle\mathrm{Q}_{2}\left(v_{2}\right)+\xi_{2}, v_{2}-\mathrm{u}_{2}\right\rangle_{\mathrm{u}_{2}^{*} \times \mathrm{u}_{2}+\phi_{2}\left(v_{2}\right)-\phi_{2}\left(\mathrm{u}_{2}\right) \geqslant 0}
\end{array}\right.
$$

Utilizing Lemma $2.10(\mathrm{v})$, we obtain that

$$
\left\{\begin{array}{l}
\mathrm{J}_{1}^{\circ}\left(v_{1}, v_{2} ; v_{1}-\mathrm{u}_{1}\right) \geqslant\left\langle\xi_{1}, v_{1}-\mathrm{u}_{1}\right\rangle \mathrm{u}_{1}^{*} \times \mathrm{u}_{1}, \\
\mathrm{~J}_{2}^{\circ}\left(v_{1}, v_{2} ; v_{2}-\mathrm{u}_{2}\right) \geqslant\left\langle\xi_{2}, v_{2}-\mathrm{u}_{2}\right\rangle \mathrm{u}_{2}^{*} \times \mathrm{u}_{2}
\end{array}\right.
$$

which together with (3.4), implies that $\mathbf{u}=\left(\mathrm{u}_{1}, \mathrm{u}_{2}\right) \in \mathrm{K}_{1} \times \mathrm{K}_{2}$ is a solution of problem (3.1).

All in all, we show that $\mathbf{u}=\left(\mathrm{u}_{1}, \mathrm{u}_{2}\right) \in \mathrm{K}_{1} \times \mathrm{K}_{2}$ is a solution of (SHVI) if and only if it is a solution of (SGMVI).

Next, in order to establish the other assertions of the theorem, we first suppose that the set $K_{i}$ is bounded in $U_{i}$ for $i=1,2$. We introduce the set-valued mapping $G: K_{1} \times K_{2} \rightarrow P\left(K_{1} \times K_{2}\right)$ by

$$
\begin{aligned}
\mathrm{G}(\mathbf{v}):=\{\mathbf{u}= & \left(\mathrm{u}_{1}, \mathrm{u}_{2}\right) \in \mathrm{K}_{1} \times \mathrm{K}_{2}: \quad \exists\left(\xi_{1}, \xi_{2}\right) \in \partial_{1} \mathrm{~J}(\mathbf{v}) \times \partial_{2} \mathrm{~J}(\mathbf{v}) \text { s.t. } \\
& \left\langle\mathrm{Q}_{1}\left(v_{1}\right)+\xi_{1}, v_{1}-\mathrm{u}_{1}\right\rangle \mathrm{u}_{1}^{*} \times \mathrm{u}_{1}+\phi_{1}\left(v_{1}\right)-\phi_{1}\left(\mathrm{u}_{1}\right) \geqslant 0, \\
& \left.\left\langle\mathrm{Q}_{2}\left(v_{2}\right)+\xi_{2}, v_{2}-\mathrm{u}_{2}\right\rangle \mathrm{u}_{2}^{*} \times \mathrm{u}_{2}+\phi_{2}\left(v_{2}\right)-\phi_{2}\left(\mathrm{u}_{2}\right) \geqslant 0\right\}
\end{aligned}
$$

for all $\mathbf{v}=\left(v_{1}, v_{2}\right) \in K_{1} \times K_{2}$. In this respect we notice that $G(\mathbf{v})$ is convex and $\mathbf{v} \in G(\mathbf{v})$ whenever $\mathbf{v}=\left(v_{1}, v_{2}\right) \in \mathrm{K}_{1} \times \mathrm{K}_{2}$. The set $\mathrm{G}(\mathbf{v})$ is weakly closed in $\mathrm{U}=\mathrm{U}_{1} \times \mathrm{U}_{2}$ for all $\mathbf{v}=\left(v_{1}, v_{2}\right) \in \mathrm{K}_{1} \times \mathrm{K}_{2}$. Indeed, taking a sequence $\left\{\mathbf{u}^{n}\right\} \subset \mathrm{G}(\mathbf{v})$ with $\mathbf{u}^{\mathrm{n}}=\left(\mathrm{u}_{1}^{\mathrm{n}}, \mathrm{u}_{2}^{\mathrm{n}}\right) \rightarrow \mathbf{u}=\left(\mathrm{u}_{1}, \mathrm{u}_{2}\right)$ in $\mathrm{U}=\mathrm{U}_{1} \times \mathrm{U}_{2}$, we know that there exists $\left(\xi_{1}, \xi_{2}\right) \in \partial_{1} J(\mathbf{v}) \times \partial_{2} J(\mathbf{v})$ such that

$$
\left\{\begin{array}{l}
\left\langle\mathrm{Q}_{1}\left(v_{1}\right)+\xi_{1}, v_{1}-\mathrm{u}_{1}^{\mathrm{n}}\right\rangle \mathrm{u}_{1}^{*} \times \mathrm{u}_{1}+\phi_{1}\left(v_{1}\right)-\phi_{1}\left(\mathrm{u}_{1}^{\mathrm{n}}\right) \geqslant 0, \\
\left\langle\mathrm{Q}_{2}\left(v_{2}\right)+\xi_{2}, v_{2}-\mathrm{u}_{2}^{\mathrm{n}}\right\rangle \mathrm{u}_{2}^{*} \times \mathrm{u}_{2}+\phi_{2}\left(v_{2}\right)-\phi_{2}\left(\mathrm{u}_{2}^{\mathrm{n}}\right) \geqslant 0 .
\end{array}\right.
$$

Taking the limit as $n \rightarrow \infty$ at both sides of the inequalities in (3.5), on the basis of assumption (ii), results in

$$
\left\{\begin{array}{l}
\left\langle\mathrm{Q}_{1}\left(v_{1}\right)+\xi_{1}, v_{1}-\mathrm{u}_{1}\right\rangle \mathrm{u}_{1}^{*} \times \mathrm{u}_{1}+\phi_{1}\left(v_{1}\right)-\phi_{1}\left(\mathrm{u}_{1}\right) \geqslant 0 \\
\left\langle\mathrm{Q}_{2}\left(v_{2}\right)+\xi_{2}, v_{2}-\mathrm{u}_{2}\right\rangle \mathrm{u}_{2}^{*} \times \mathrm{u}_{2}+\phi_{2}\left(v_{2}\right)-\phi_{2}\left(\mathrm{u}_{2}\right) \geqslant 0
\end{array}\right.
$$

which means that $\mathbf{u}=\left(\mathrm{u}_{1}, \mathrm{u}_{2}\right) \in \mathrm{G}(\mathbf{v})$.

Now we show that $G$ is a KKM mapping. Arguing by contradiction, assume that there exist a finite subset $\left\{\mathbf{v}^{1}, \mathbf{v}^{2}, \ldots, \mathbf{v}^{\mathfrak{n}}\right\} \subset \mathrm{K}_{1} \times \mathrm{K}_{2}$ and $\mathbf{u}^{0}=\sum_{\mathrm{m}=1}^{\mathfrak{n}} \lambda_{\mathrm{m}} \mathbf{v}^{\mathrm{m}}$ with $\mathbf{v}^{\mathrm{m}}=\left(v_{1}^{\mathrm{m}}, v_{2}^{\mathrm{m}}\right), \lambda_{\mathrm{m}} \in[0,1]$ and $\sum_{m=1}^{\mathfrak{n}} \lambda_{\mathrm{m}}=$ 
1 satisfying $\mathbf{u}^{0}=\left(u_{1}^{0}, u_{2}^{0}\right) \notin \bigcup_{m=1}^{n} G\left(\mathbf{v}^{m}\right)$, that is, for all $m \in\{1,2, \ldots, n\}$, there exists $\left(\xi_{1}^{m}, \xi_{2}^{m}\right) \in \partial_{1} J\left(\mathbf{v}^{m}\right) \times$ $\partial_{2} J\left(\mathbf{v}^{\mathrm{m}}\right)$ such that

$$
\left\{\begin{array}{l}
\left\langle\mathrm{Q}_{1}\left(v_{1}^{\mathrm{m}}\right)+\xi_{1}^{\mathrm{m}}, v_{1}^{\mathrm{m}}-\mathrm{u}_{1}^{0}\right\rangle \mathrm{u}_{1}^{*} \times \mathrm{u}_{1}+\phi_{1}\left(v_{1}^{\mathrm{m}}\right)-\phi_{1}\left(\mathrm{u}_{1}^{0}\right)<0, \\
\left\langle\mathrm{Q}_{2}\left(v_{2}^{\mathrm{m}}\right)+\xi_{2}^{\mathrm{m}}, v_{2}^{\mathrm{m}}-\mathrm{u}_{2}^{0}\right\rangle \mathrm{u}_{2}^{*} \times \mathrm{u}_{2}+\phi_{2}\left(v_{2}^{\mathrm{m}}\right)-\phi_{2}\left(\mathrm{u}_{2}^{0}\right)<0 .
\end{array}\right.
$$

For $i=1,2$, by the monotonicity of $Q_{i}$ and $\partial_{i} J$, we deduce that for each $m \in\{1,2, \ldots, n\}$ and any $\zeta_{i}^{0} \in \partial_{i} J\left(\mathbf{u}^{0}\right)$ there hold

$$
\left\langle\mathrm{Q}_{i}\left(\mathrm{u}_{i}^{0}\right)-\mathrm{Q}_{i}\left(v_{i}^{m}\right), v_{i}^{m}-u_{i}^{0}\right\rangle u_{i}^{*} \times u_{i} \leqslant 0 \text { and }\left\langle\zeta_{i}^{0}-\xi_{i}^{m}, v_{i}^{m}-u_{i}^{0}\right\rangle u_{i}^{*} \times u_{i} \leqslant 0 .
$$

Then combining (3.6) and (3.7) implies that for all $m \in\{1,2, \ldots, n\}$,

$$
\left\{\begin{array}{l}
\left\langle\mathrm{Q}_{1}\left(\mathrm{u}_{1}^{0}\right)+\zeta_{1}^{0}, v_{1}^{\mathrm{m}}-\mathrm{u}_{1}^{0}\right\rangle \mathrm{u}_{1}^{*} \times \mathrm{u}_{1}+\phi_{1}\left(v_{1}^{\mathrm{m}}\right)-\phi_{1}\left(\mathrm{u}_{1}^{0}\right)<0, \\
\left\langle\mathrm{Q}_{2}\left(\mathrm{u}_{2}^{0}\right)+\zeta_{2}^{0}, v_{2}^{\mathrm{m}}-\mathrm{u}_{2}^{0}\right\rangle \mathrm{u}_{2}^{*} \times \mathrm{u}_{2}+\phi_{2}\left(v_{2}^{\mathrm{m}}\right)-\phi_{2}\left(\mathrm{u}_{2}^{0}\right)<0,
\end{array}\right.
$$

from which it arises the contradiction, that is, for $i=1,2$,

$$
\begin{aligned}
0 & =\left\langle Q_{i}\left(u_{i}^{0}\right)+\zeta_{i}^{0}, u_{i}^{0}-u_{i}^{0}\right\rangle u_{i}^{*} \times u_{i}+\phi_{i}\left(u_{i}^{0}\right)-\phi_{i}\left(u_{i}^{0}\right) \\
& \leqslant \sum_{m=1}^{n} \lambda_{m}\left[\left\langle Q_{i}\left(u_{i}^{0}\right)+\zeta_{i}^{0}, v_{i}^{m}-u_{i}^{0}\right\rangle u_{i}^{*} \times u_{i}+\phi_{i}\left(v_{i}^{m}\right)-\phi_{i}\left(u_{i}^{0}\right)\right]<0 .
\end{aligned}
$$

Therefore $\mathrm{G}$ is a KKM mapping.

Since $K_{i}$ is bounded, closed, and convex in the reflexive Banach space $U_{i}$ for $i=1,2$, it follows that $\mathrm{K}_{1} \times \mathrm{K}_{2}$ is weakly compact in the reflexive Banach space $\mathrm{U}=\mathrm{U}_{1} \times \mathrm{U}_{2}$. Consequently, $\mathrm{G}(\mathbf{v})$ is weakly compact in $\mathrm{U}=\mathrm{U}_{1} \times \mathrm{U}_{2}$ for each $\mathbf{v}=\left(v_{1}, v_{2}\right) \in \mathrm{K}_{1} \times \mathrm{K}_{2}$. We are in a position to apply Lemma 2.1 ensuring that $\bigcap_{\mathbf{v} \in K_{1} \times K_{2}} G(\mathbf{v}) \neq \emptyset$. Hence the solution set of problem (SGMVI) is nonempty, so the same is true for the solution set of problem (SHVI).

Now we suppose that the set $K_{i}$ is unbounded in $U_{i}$ for $i=1,2$. For every integer $n \geqslant 1$, using the element $\mathbf{u}^{0}:=\left(u_{1}^{0}, u_{2}^{0}\right) \in K_{1} \times K_{2}$ given in assumption (v), we know that $K_{i}^{n}:=\left\{x_{i} \in K_{i}:\left\|x_{i}-u_{i}^{0}\right\| u_{i} \leqslant n\right\}$ is a bounded, closed, and convex subset of $U_{i}$ for $i=1,2$. According to the proceeding proof, we can find $\mathbf{u}^{\mathrm{n}}=\left(\mathrm{u}_{1}^{\mathrm{n}}, \mathrm{u}_{2}^{\mathrm{n}}\right) \in \mathrm{K}_{1}^{\mathrm{n}} \times \mathrm{K}_{2}^{\mathrm{n}}$ such that

$$
\left\{\begin{array}{l}
\left\langle\mathrm{Q}_{1}\left(\mathrm{u}_{1}^{\mathrm{n}}\right), v_{1}-\mathrm{u}_{1}^{\mathrm{n}}\right\rangle \mathrm{u}_{1}^{*} \times \mathrm{u}_{1}+\mathrm{J}_{1}^{\circ}\left(\mathrm{u}_{1}^{\mathrm{n}}, \mathrm{u}_{2}^{\mathrm{n}} ; v_{1}-\mathrm{u}_{1}^{\mathrm{n}}\right)+\phi_{1}\left(v_{1}\right)-\phi_{1}\left(\mathrm{u}_{1}^{\mathrm{n}}\right) \geqslant 0, \forall v_{1} \in \mathrm{K}_{1}^{\mathrm{n}}, \\
\left\langle\mathrm{Q}_{2}\left(\mathrm{u}_{2}^{\mathrm{n}}\right), v_{2}-\mathrm{u}_{2}^{\mathrm{n}}\right\rangle \mathrm{u}_{2}^{*} \times \mathrm{u}_{2}+\mathrm{J}_{2}^{\circ}\left(\mathrm{u}_{1}^{\mathrm{n}}, \mathrm{u}_{2}^{n} ; v_{2}-\mathrm{u}_{2}^{\mathrm{n}}\right)+\phi_{2}\left(v_{2}\right)-\phi_{2}\left(\mathrm{u}_{2}^{\mathrm{n}}\right) \geqslant 0, \forall v_{2} \in \mathrm{K}_{2}^{\mathrm{n}} .
\end{array}\right.
$$

We claim that there exists an integer $k \geqslant 1$ such that

$$
\max _{i \in\{1,2\}}\left\|u_{i}^{k}-u_{i}^{0}\right\|_{u_{i}}<k \text {. }
$$

Arguing by contradiction, assume that $\max _{i \in\{1,2\}}\left\|u_{i}^{n}-u_{i}^{0}\right\| u_{i}=n$ for every $n \geqslant 1$. Inserting $v_{i}=u_{i}^{0}$ for $i=1,2$ in (3.8), it turns out

$$
\left\{\begin{array}{l}
\left\langle\mathrm{Q}_{1}\left(\mathrm{u}_{1}^{\mathfrak{n}}\right), \mathrm{u}_{1}^{0}-\mathrm{u}_{1}^{\mathfrak{n}}\right\rangle \mathrm{u}_{1}^{*} \times \mathrm{u}_{1}+\mathrm{J}_{1}^{\circ}\left(\mathrm{u}_{1}^{\mathfrak{n}}, \mathrm{u}_{2}^{\mathrm{n}} ; \mathrm{u}_{1}^{0}-\mathrm{u}_{1}^{\mathfrak{n}}\right)+\phi_{1}\left(\mathrm{u}_{1}^{0}\right)-\phi_{1}\left(\mathrm{u}_{1}^{\mathfrak{n}}\right) \geqslant 0, \\
\left\langle\mathrm{Q}_{2}\left(\mathrm{u}_{2}^{\mathfrak{n}}\right), \mathrm{u}_{2}^{0}-\mathrm{u}_{2}^{\mathfrak{n}}\right\rangle \mathrm{u}_{2}^{*} \times \mathrm{u}_{2}+\mathrm{J}_{2}^{\circ}\left(\mathrm{u}_{1}^{\mathfrak{n}}, \mathrm{u}_{2}^{\mathrm{n}} ; \mathrm{u}_{2}^{0}-\mathrm{u}_{2}^{\mathfrak{n}}\right)+\phi_{2}\left(\mathrm{u}_{2}^{0}\right)-\phi_{2}\left(\mathrm{u}_{2}^{\mathfrak{n}}\right) \geqslant 0,
\end{array}\right.
$$

which contradicts assumption (v) provided $n$ is sufficiently large. Hence the claim in (3.9) holds true.

Let $\mathbf{x}=\left(x_{1}, x_{2}\right) \in K_{1} \times K_{2}$. By (3.9), we have for sufficiently small $t>0$ that

$$
\max _{i \in\{1,2\}}\left\|u_{i}^{k}+t\left(x_{i}-u_{i}^{k}\right)-u_{i}^{0}\right\| u_{i}<k \text {. }
$$

This enables us to set $v_{i}=u_{i}^{k}+t\left(x_{i}-u_{i}^{k}\right)$ in (3.8) for $n=k$ and $i=1,2$, which together with the convexity of $\phi_{i}$ and the positive homogeneousness of $J_{i}^{\circ}\left(u_{1}^{k}, u_{2}^{k} ; \cdot\right)$, implies that

$$
\left\{\begin{array}{l}
\left\langle Q_{1}\left(u_{1}^{k}\right), x_{1}-u_{1}^{k}\right\rangle u_{1}^{*} \times u_{1}+J_{1}^{o}\left(u_{1}^{k}, u_{2}^{k} ; x_{1}-u_{1}^{k}\right)+\phi_{1}\left(x_{1}\right)-\phi_{1}\left(u_{1}^{k}\right) \geqslant 0, \forall x_{1} \in K_{1}, \\
\left\langle Q_{2}\left(u_{2}^{k}\right), x_{2}-u_{2}^{k}\right\rangle u_{2}^{*} \times u_{2}+J_{2}^{o}\left(u_{1}^{k}, u_{2}^{k} ; x_{2}-u_{2}^{k}\right)+\phi_{2}\left(x_{2}\right)-\phi_{2}\left(u_{2}^{k}\right) \geqslant 0, \forall x_{2} \in K_{2} .
\end{array}\right.
$$

We conclude that $\mathbf{u}=\left(u_{1}^{k}, u_{2}^{k}\right)$ is a solution of problem (SHVI). 
On the basis of the equivalence between problems (SHVI) and (SGMVI), it is readily seen from (SGMVI), in conjunction with assumption (ii), that the solution set of (SHVI) is closed and convex in $\mathrm{U}=\mathrm{U}_{1} \times \mathrm{U}_{2}$. This completes the proof.

Remark 3.2. Theorem 3.1 extends the results in Costea and Radulescu [5], Liu and Zeng [18], and Liu et al. [19]. Many important situations are incorporated in Theorem 3.1. Assertion (3.1) is an extension of Minty's technique. Assumption (v) expresses a generalized coercivity condition. Related results can be founded in [13].

The first part of the proof of Theorem 3.1 implies the following corollary.

Corollary 3.3. Let $\mathrm{J}: \mathrm{U} \rightarrow \mathbf{R}$ be a locally Lipschitz functional on $\mathrm{U}=\mathrm{U}_{1} \times \mathrm{U}_{2}$. Let $\mathrm{K}_{\mathrm{i}}$ be a nonempty compact and convex subset of a real Banach space $U_{i}$ for $i=1,2$. Assume that for $i=1,2, Q_{i}: K_{i} \rightarrow U_{i}^{*}, \phi_{i}: U_{i} \rightarrow \mathbf{R}$ and $\mathrm{J}: \mathrm{U} \rightarrow \mathbf{R} \cup\{+\infty\}$ verify conditions (i), (ii), (iii), (iv) in Theorem 3.1. Then the conclusion of Theorem 3.1 is valid.

Now we establish some additional properties of the solution set for a class of systems of hemivariational inequalities that are closely related to problem (SEESHVI).

Theorem 3.4. Let $\mathrm{J}: \mathrm{U} \rightarrow \mathbf{R}$ be a locally Lipschitz functional on $\mathrm{U}=\mathrm{U}_{1} \times \mathrm{U}_{2}$. Let $\mathrm{K}_{\mathrm{i}}$ be a nonempty compact and convex subset of a real Banach space $U_{i}$ for $i=1,2$. Assume that $i=1,2, V_{i}$ be a real separable Banach space and, for some $\mathrm{T}>0$, the mapping $\mathrm{g}_{\mathrm{i}}:[0, \mathrm{~T}] \times \mathrm{V}_{1} \times \mathrm{V}_{2} \times \mathrm{K}_{\mathrm{i}} \rightarrow \mathrm{U}_{\mathrm{i}}^{*}$ is such that $\mathrm{g}_{\mathrm{i}}\left(\cdot, \cdot, \cdot, \mathrm{u}_{\mathrm{i}}\right)$ is continuous from $[0, \mathrm{~T}] \times \mathrm{V}_{1} \times \mathrm{V}_{2}$ to $\mathrm{U}_{i}^{*}$ endowed with the weak topology whenever $\mathrm{u}_{\mathrm{i}} \in \mathrm{K}_{\mathrm{i}}$. In addition, we assume that for every $\left(\mathrm{t}, \mathrm{x}_{1}, \mathrm{x}_{2}\right) \in[0, \mathrm{~T}] \times \mathrm{V}_{1} \times \mathrm{V}_{2}$ the mappings $\mathrm{Q}_{\mathrm{i}}:=\mathrm{g}_{\mathrm{i}}\left(\mathrm{t}, \mathrm{x}_{1}, \mathrm{x}_{2}, \cdot\right), \phi_{\mathrm{i}}: \mathrm{U}_{\mathrm{i}} \rightarrow \mathbf{R} \cup\{+\infty\}$, and $\mathrm{J}: \mathrm{U} \rightarrow \mathbf{R}$ satisfy hypotheses (i), (ii), (iii), (iv) in Theorem 3.1. Then the set-valued mapping $\mathcal{U}:[0, \mathrm{~T}] \times \mathrm{V}_{1} \times \mathrm{V}_{2} \rightarrow \mathrm{P}\left(\mathrm{K}_{1} \times \mathrm{K}_{2}\right)$ defined by

$$
\begin{aligned}
& \mathcal{U}\left(\mathrm{t}, \mathrm{x}_{1}, \mathrm{x}_{2}\right):=\left\{\mathbf{u}=\left(\mathrm{u}_{1}, \mathrm{u}_{2}\right) \in \mathrm{K}_{1} \times \mathrm{K}_{2}:\left\langle\mathrm{g}_{1}\left(\mathrm{t}, \mathrm{x}_{1}, \mathrm{x}_{2}, \mathrm{u}_{1}\right), v_{1}-\mathrm{u}_{1}\right\rangle \mathrm{u}_{1}^{*} \times \mathrm{u}_{1}\right. \\
&+\mathrm{J}_{1}^{\circ}\left(\mathrm{u}_{1}, \mathrm{u}_{2} ; v_{1}-\mathrm{u}_{1}\right)+\phi_{1}\left(v_{1}\right)-\phi_{1}\left(\mathrm{u}_{1}\right) \geqslant 0, \quad \forall v_{1} \in \mathrm{K}_{1}, \\
&\left.\left\langle\mathrm{~g}_{2}\left(\mathrm{t}, \mathrm{x}_{1}, \mathrm{x}_{2}, \mathrm{u}_{2}\right), v_{2}-\mathrm{u}_{2}\right\rangle \mathrm{u}_{2}^{*} \times \mathrm{u}_{2}+\mathrm{J}_{2}^{\circ}\left(\mathrm{u}_{1}, \mathrm{u}_{2} ; v_{2}-\mathrm{u}_{2}\right)+\phi_{2}\left(v_{2}\right)-\phi_{2}\left(\mathrm{u}_{2}\right) \geqslant 0, \forall v_{2} \in \mathrm{K}_{2}\right\}
\end{aligned}
$$

for all $\left(\mathrm{t}, \mathrm{x}_{1}, \mathrm{x}_{2}\right) \in[0, \mathrm{~T}] \times \mathrm{V}_{1} \times \mathrm{V}_{2}$ fulfills:

(a) $\mathcal{U}$ is upper semicontinuous;

(b) $\mathcal{U}$ is superpositionally measurable in the sense of Definition 2.2.

Proof. Let $\mathrm{V}=\mathrm{V}_{1} \times \mathrm{V}_{2}$, endowed with the norm defined by $\|\mathbf{x}\|_{V}:=\left\|\mathrm{x}_{1}\right\| \mathrm{V}_{1}+\left\|\mathrm{x}_{2}\right\|_{\mathrm{V}_{2}}$ for all $\mathbf{x}=\left(\mathrm{x}_{1}, \mathrm{x}_{2}\right) \in$ $V$, where $V$ is a Banach space (see e.g., [34]). Corollary 3.3 guarantees that for every $t \in[0, T]$ and $\mathbf{x}=\left(x_{1}, x_{2}\right) \in V$ the set $U(t, x)$ is nonempty, so the mapping $\mathcal{U}:[0, T] \times V \rightarrow P\left(K_{1} \times K_{2}\right)$ is well-defined. In order to prove (a), we need to check that for each closed subset $C \subset K_{1} \times K_{2}$, the set $\mathcal{U}^{-}(C):=\{(t, x)$ : $\mathcal{U}(t, \mathbf{x}) \cap C \neq \emptyset\}$ is closed in $\mathbf{R} \times V$. To this end, let a sequence $\left\{\left(t_{n}, \mathbf{x}^{\mathfrak{n}}\right)\right\} \subset \mathcal{U}^{-}(C)$ satisfies $\left(t_{n}, \mathbf{x}^{\mathfrak{n}}\right) \rightarrow(t, \mathbf{x})$ in $\mathbf{R} \times V$ where $\mathbf{x}^{n}=\left(x_{1}^{n}, x_{2}^{n}\right)$ and $\mathbf{x}=\left(x_{1}, x_{2}\right)$. Thus we can choose $\mathbf{u}^{n}=\left(u_{1}^{n}, u_{2}^{n}\right) \in \mathcal{U}\left(t_{n}, x^{n}\right) \cap C$. Then (3.10) and Corollary 3.3 render

$$
\left\{\begin{array}{l}
\left\langle g_{1}\left(t_{n}, x^{n}, u_{1}^{n}\right), v_{1}-u_{1}^{n}\right\rangle u_{1}^{*} \times u_{1}+J_{1}^{\circ}\left(u_{1}^{n}, u_{2}^{n} ; v_{1}-u_{1}^{n}\right)+\phi_{1}\left(v_{1}\right)-\phi_{1}\left(u_{1}^{n}\right) \geqslant 0, \forall v_{1} \in K_{1}, \\
\left\langle g_{2}\left(t_{n}, x^{n}, u_{2}^{n}\right), v_{2}-u_{2}^{n}\right\rangle u_{2}^{*} \times u_{2}+J_{2}^{\circ}\left(u_{1}^{n}, u_{2}^{n} ; v_{2}-u_{2}^{n}\right)+\phi_{2}\left(v_{2}\right)-\phi_{2}\left(u_{2}^{n}\right) \geqslant 0, \forall v_{2} \in K_{2} .
\end{array}\right.
$$

By the compactness of $K_{1} \times K_{2}$, we may pass to a relabeled subsequence with $\mathbf{u}^{n} \rightarrow \mathbf{u}$ in $\mathrm{U}$ for some $\mathbf{u}=\left(\mathfrak{u}_{1}, \mathfrak{u}_{2}\right) \in \mathbf{C}$. Utilizing Lemma 3.6 of [28] we obtain that for $\mathfrak{i}=1,2$

$$
\limsup _{n \rightarrow \infty} J_{i}^{\circ}\left(u_{1}^{n}, u_{2}^{n} ; v_{i}-u_{i}^{n}\right) \leqslant J_{i}^{\circ}\left(u_{1}, u_{2} ; v_{i}-u_{i}\right) .
$$

Taking the limsup as $n \rightarrow \infty$ at both sides of the inequalities in (3.11), from our assumptions we obtain

$$
\left\{\begin{array}{l}
\left\langle\mathrm{g}_{1}\left(\mathrm{t}, \mathbf{x}, \mathrm{u}_{1}\right), v_{1}-\mathrm{u}_{1}\right\rangle \mathrm{u}_{1}^{*} \times \mathrm{u}_{1}+\mathrm{J}_{1}^{\circ}\left(\mathrm{u}_{1}, \mathrm{u}_{2} ; v_{1}-\mathrm{u}_{1}\right)+\phi_{1}\left(v_{1}\right)-\phi_{1}\left(\mathrm{u}_{1}\right) \geqslant 0, \forall v_{1} \in \mathrm{K}_{1}, \\
\left\langle\mathrm{~g}_{2}\left(\mathrm{t}, \mathbf{x}, \mathrm{u}_{2}\right), v_{2}-\mathrm{u}_{2}\right\rangle \mathrm{u}_{2}^{*} \times \mathrm{u}_{2}+\mathrm{J}_{2}^{\circ}\left(\mathrm{u}_{1}, \mathrm{u}_{2} ; v_{2}-\mathrm{u}_{2}\right)+\phi_{2}\left(v_{2}\right)-\phi_{2}\left(\mathrm{u}_{2}\right) \geqslant 0, \forall v_{2} \in \mathrm{K}_{2} .
\end{array}\right.
$$

This reads as $\mathbf{u}=\left(\mathfrak{u}_{1}, \mathfrak{u}_{2}\right) \in \mathcal{U}(t, \mathbf{x}) \cap C$ whence $(t, \mathbf{x}) \in \mathcal{U}^{-}(C)$. Thereby we get part (a). 
Finally, we note that assertion (a) allows us to apply Theorem 2.3, which ensures that (b) holds true. This completes the proof.

\section{Existence results}

In this section we focus on problem (SEESHVI) with the set of constraints $\mathrm{K}=\mathrm{K}_{1} \times \mathrm{K}_{2} \subset \mathrm{U}=\mathrm{U}_{1} \times \mathrm{U}_{2}$. For $i=1,2$, we impose the following assumptions on the mapping $f_{i}:[0, T] \times V \times U \rightarrow V_{i}$ in (1.1) with $\mathrm{V}=\mathrm{V}_{1} \times \mathrm{V}_{2}$ :

(f1) for every $(t, x) \in[0, T] \times V$ and every convex set $D \subset K$, the set $f_{i}(t, x, D)$ is convex in $V_{i}$ with $\mathbf{x}=\left(\mathrm{x}_{1}, \mathrm{x}_{2}\right)$;

(f2) there exists $\psi_{i} \in \mathrm{L}^{1}([0, \mathrm{~T}])$ such that

$$
\left\|f_{i}(t, x, \mathbf{u})\right\|_{v_{i}} \leqslant \psi_{i}(t)\left(1+\left\|x_{i}\right\|_{v_{i}}\right), \forall(t, x, u) \in[0, T] \times V \times K,
$$

with $\mathbf{x}=\left(\mathrm{x}_{1}, \mathrm{x}_{2}\right)$ and $\mathbf{u}=\left(\mathrm{u}_{1}, \mathrm{u}_{2}\right)$

(f3) $f_{i}(\cdot, \mathbf{x}, \mathbf{u}):[0, T] \rightarrow V_{i}$ is measurable for every $(\mathbf{x}, \mathbf{u}) \in \mathrm{V} \times \mathrm{U}$;

(f4) $f_{i}(t, \cdot, \cdot): V \times U \rightarrow V_{i}$ is continuous for a.e. $t \in[0, T]$;

(f5) there exists $k_{i} \in L^{1}([0, T])$ such that

$$
\left\|f_{i}(t, x, u)-f_{i}(t, y, u)\right\| v_{i} \leqslant k_{i}(t)\left\|x_{i}-y_{i}\right\| v_{i} \text { for a.e. } t \in[0, T], \forall \mathbf{x}, \mathbf{y} \in V, \forall \mathbf{u} \in K,
$$

with $\mathbf{x}=\left(x_{1}, x_{2}\right)$ and $\mathbf{y}=\left(y_{1}, y_{2}\right)$.

Remark 4.1. A special case of (f1) is when $f(t, x, \cdot): K^{\prime} \rightarrow E_{1}$ is affine for all $(t, x) \in[0, T] \times E$. In Pang and Stewart [25] and Liu et al. [17] it is utilized an $f$ of the form $f(t, x, u)=g(t, x)+B(t, x) u$.

For $i=1,2$, we set forth relevant properties of the set-valued mapping $F_{i}:[0, T] \times V \rightarrow P\left(V_{i}\right)$ given by $F_{i}(t, x)=f_{i}(t, x, \mathcal{U}(t, x))$, with $\mathcal{U}$ introduced in (3.10).

Lemma 4.2. Assume that for $\mathrm{i}=1,2, \mathrm{~V}_{i}$ and $\mathrm{U}_{i}$ are real Banach spaces, with $\mathrm{V}_{i}$ separable, and $\mathrm{K}_{i}$ is a nonempty compact and convex subset of $\mathrm{U}_{i}$. Assume that the hypotheses of Theorem 3.4 and conditions (f1)-(f5) above are satisfied. Then, for $i=1,2$ there hold:

(i) for all $(\mathrm{t}, \mathbf{x}) \in[0, \mathrm{~T}] \times \mathrm{V}, \mathrm{F}_{\mathrm{i}}(\mathrm{t}, \mathbf{x}) \in \mathrm{Kv}\left(\mathrm{V}_{\mathrm{i}}\right)$;

(ii) for every $\mathbf{x} \in \mathrm{V}, \mathrm{F}_{\mathrm{i}}(\cdot, \mathbf{x})$ has a strongly measurable selection;

(iii) for a.e. $\mathrm{t} \in[0, \mathrm{~T}], \mathrm{F}_{\mathrm{i}}(\mathrm{t}, \cdot)$ is upper semicontinuous;

(iv) for every bounded subset $\mathrm{D} \subset \mathrm{V}$, there exists $\mathrm{l} \in \mathrm{L}^{1}([0, \mathrm{~T}])$ such that

$$
\chi\left(F_{1}(t, D) \times F_{2}(t, D)\right) \leqslant l(t) \chi(D) \text { for a.e. } t \in[0, T],
$$

where $\mathrm{x}$ is the Hausdorff MNC in $\mathrm{V}$.

Proof.

(i) Corollary 3.3 and Theorem 3.4 ensure that the set-valued mapping $\mathcal{U}$ takes its values in $K v(K)$ with $K=K_{1} \times K_{2}$. Then, for $i=1,2$, hypotheses (f1) and (f4) imply that $F_{i}(t, x) \in K v\left(V_{i}\right)$ for all $(t, x) \in[0, T] \times V$.

(ii) By virtue of (f3) and (f4), we have that $f_{i}(\cdot, \mathbf{x}, \cdot):[0, T] \times U \rightarrow V_{i}$ satisfies the Caratheodory condition. Notice that $U(t, \mathbf{x}) \in \mathrm{K}(\mathrm{U})$ for all $(\mathrm{t}, \mathbf{x}) \in[0, T] \times \mathrm{V}$. Invoking assertion (a) of Theorem 3.4 and applying Theorem 2.3, we infer that $F_{i}(\cdot, \mathbf{x})=f_{i}(\cdot, \mathbf{x}, \mathcal{U}(\cdot, \mathbf{x}))$ is measurable for every $\mathbf{x} \in \mathrm{V}$, so it is strongly measurable because $V_{i}$ is separable for $i=1,2$. Therefore, for $i=1,2$, taking (i) into account, $F_{i}(\cdot, x)$ has a strongly measurable selection whenever $\mathbf{x} \in \mathrm{V}$ (see [12]). 
(iii) For any fixed $t \in[0, T]$, consider the mappings $\mathcal{F}_{1}=(\cdot, \mathcal{U}(t, \cdot)): \mathrm{V} \rightarrow \mathrm{P}(\mathrm{V} \times \mathrm{K})$ and $\mathcal{F}_{2, \mathrm{i}}=\mathrm{f}_{\mathrm{i}}(\mathrm{t}, \cdot, \cdot)$ : $\mathrm{V} \times \mathrm{U} \rightarrow \mathrm{V}_{i}$. As known from (b) in Theorem 3.4, the set-valued mapping $\mathcal{F}_{1}$ is upper semicontinuous, whereas hypothesis (f4) guarantees that $\mathcal{F}_{2, i}$ is continuous. Then, for $i=1,2$, since $F_{i}(t, \cdot)=\mathcal{F}_{2, i} \circ \mathcal{F}_{1}$, we can infer that $F_{i}(t, \cdot)$ is upper semicontinuous.

(iv) For $i=1,2$ and any $t \in[0, T]$, in view of Theorem 3.4 we can consider the set-valued mapping $G_{i}: V \times V \rightarrow K v\left(V_{i}\right)$ given by $G_{i}(x, y)=f_{i}(t, y, U(t, x))$ for all $(x, y) \in V \times V$. We note that for each bounded subset $D \subset V$ it follows that for $i=1,2, G_{i}(D, y)=f_{i}(t, y, U(t, D))$ is relatively compact in $V_{i}$ whenever $y \in V$. This is true because $U(t, D) \subset K$ and $K=K_{1} \times K_{2}$ is compact. Hence requirement (2) in Theorem 2.6 is verified.

Let $\mathbf{x}, \mathbf{y}^{1}, \mathbf{y}^{2} \in V$. If for $i=1,2, z_{i}^{1} \in G_{i}\left(\mathbf{x}, \mathbf{y}^{1}\right)$, there is $\mathbf{u} \in \mathcal{U}(t, \mathbf{x})$ such that $z_{i}^{1}=f_{i}\left(t, \mathbf{y}^{1}, \mathbf{u}\right)$, and so $z_{i}^{2}=f_{i}\left(t, y^{2}, \mathbf{u}\right) \in G_{i}\left(x, y^{2}\right)$. Assumption (f5) enables us to write for $i=1,2$,

$$
\left\|z_{i}^{1}-z_{i}^{2}\right\|_{v_{i}}=\left\|f_{i}\left(t, y^{1}, \mathbf{u}\right)-f_{i}\left(t, y^{2}, \mathbf{u}\right)\right\| v_{i} \leqslant k_{i}(t)\left\|y_{i}^{1}-y_{i}^{2}\right\|_{v_{i}},
$$

which leads to the conclusion that $G_{i}\left(x_{,} \cdot\right)$ is $k_{i}(t)$-Lipschitz with respect to the Hausdorff metric $\mathcal{H}_{i}$. In this way we have checked requirement (1) in Theorem 2.6. Consequently, we are in a position to apply Theorem 2.6 from which we obtain that the required property is fulfilled with $l=k_{1}+k_{2} \in L^{1}([0, T])$, which completes the proof.

Parts (ii) and (iii) of Lemma 4.2 provide that, under the hypotheses therein, the assumptions of Theorem 2.4 with $F_{i}$ in place of $G_{i}$ are fulfilled for $i=1,2$. Then we derive that $F_{i}(\cdot, q(\cdot))$ has strongly measurable selections for every $\mathbf{q}=\left(q_{1}, q_{2}\right) \in C([0, T] ; V)$. So, it is meaningful that for $i=1,2$ we define the set-valued mapping $\mathrm{P}_{\mathrm{F}_{i}}: \mathrm{C}([0, \mathrm{~T}] ; \mathrm{V}) \rightarrow \mathrm{P}\left(\mathrm{L}^{1}\left([0, \mathrm{~T}] ; \mathrm{V}_{i}\right)\right)$ by

$$
P_{F_{i}}(\mathbf{q}):=\left\{g_{i}: g_{i} \text { is strongly measurable and } g_{i}(t) \in F_{i}(t, q(t)) \text { for a.e. } t \in[0, T]\right\}
$$

for all $\mathbf{q}=\left(q_{1}, q_{2}\right) \in C([0, T] ; V)$. Furthermore, in view of part (i) of Lemma 4.2, we can introduce $\Gamma: \mathrm{C}([0, \mathrm{~T}] ; \mathrm{V}) \rightarrow \mathrm{K} v(\mathrm{C}([0, \mathrm{~T}] ; \mathrm{V}))$ by

$$
\begin{aligned}
& \Gamma \mathbf{x}:=\left\{\mathbf{y}=\left(\mathrm{y}_{1}, \mathrm{y}_{2}\right) \in C([0, T] ; V): y_{1}(t)=e^{A_{1} t} x_{1}^{0}+\int_{0}^{t} e^{A_{1}(t-s)} h_{1}(s) d s, \text { for some } h_{1} \in P_{F_{1}}(\mathbf{x}),\right. \\
& \left.y_{2}(t)=e^{A_{2} t} x_{2}^{0}+\int_{0}^{t} e^{A_{2}(t-s)} h_{2}(s) d s, \text { for some } h_{2} \in P_{F_{2}}(x)\right\} .
\end{aligned}
$$

Here, for $i=1,2, A_{i}: D\left(A_{i}\right) \subseteq V_{i} \rightarrow V_{i}$ is the infinitesimal generator of the $C_{0}$-semigroup $e^{A_{i} t}$ in $V_{i}$ as given in (1.1). We point out significant properties of the set-valued mapping $\Gamma$.

Theorem 4.3. Under the hypotheses of Lemma 4.2, the set-valued mapping $\Gamma$ in (4.1) is upper semicontinuous and $v$-condensing in the sense of Definition 2.7 on every closed bounded subset of $\mathrm{C}([0, \mathrm{~T}] ; \mathrm{V})$, with $v$ constructed in (2.1).

Proof. Combining Lemma 4.2.1, Corollary 5.1.2, Theorem 5.1.3 and Theorem 5.1.4 of [12] with our Lemma 4.2 leads to the stated result.

Our main result regarding problem (SEESHVI) is formulated as follows.

Theorem 4.4. Under the hypotheses of Lemma 4.2, the solution set of problem (SEESHVI) in the sense of Definition 1.2 is nonempty and the set of all mild trajectories $\mathbf{x}$ of (SEESHVI) is compact in $\mathrm{C}([0, \mathrm{~T}] ; \mathrm{V})$.

Proof. Let us associate to (SEESHVI) the following system of evolutionary differential inclusions ((SEDI), for short):

$$
\left\{\begin{array}{l}
x_{1}^{\prime}(t) \in A_{1} x_{1}(t)+F_{1}(t, x(t)), t \in[0, T], \\
x_{2}^{\prime}(t) \in A_{2} x_{2}(t)+F_{2}(t, x(t)), t \in[0, T], \\
x_{1}(0)=x_{1}^{0} \text { and } x_{2}(0)=x_{2}^{0},
\end{array}\right.
$$


with $\mathbf{x}(t)=\left(x_{1}(t), x_{2}(t)\right)$, where, as before, for $i=1,2, F_{i}(t, x)=f_{i}(t, x, U(t, x))$ with $U(t, x)$ defined in (3.10). The proof of the theorem is divided into three parts.

1. The solution set of (SEDI) is nonempty.

It is equivalent to show that the set of fixed points $\operatorname{Fix}(\Gamma)$ of $\Gamma$ in $(4.1)$ is nonempty. From Theorem 4.3 it is known that the set-valued mapping $\Gamma: \mathrm{C}([0, \mathrm{~T}] ; \mathrm{V}) \rightarrow \mathrm{Kv}(\mathrm{C}([0, \mathrm{~T}] ; \mathrm{V}))$ in $(4.1)$ is upper semicontinuous and $v$-condensing on every closed bounded subset of $C([0, T] ; V)$.

For $i=1,2$, fix a positive constant $L_{i}>0$ sufficiently large such that

$$
M_{i} \int_{0}^{t} e^{-L_{i}(t-s)} \psi_{i}(s) d s<1 \text { for all } t \in[0, T],
$$

where $\psi_{i} \in \mathrm{L}^{1}([0, T])$ is entering assumption (f2) and $M_{i}:=\max _{t \in[0, T]}\left\|e^{A_{i} t}\right\|$. According to (4.2), for $i=1,2$, we may choose $r_{i}>0$ such that

$$
M_{i}\left(\left\|x_{i}^{0}\right\| v_{i}+\left\|\psi_{i}\right\|_{L_{+}^{1}([0, T])}\right)+M_{i}\left(r_{1}+r_{2}\right) \int_{0}^{t} e^{-L_{i}(t-s)} \psi_{i}(s) d s \leqslant r_{i} \text { for all } t \in[0, T] .
$$

For the equivalent norms on the spaces $C\left([0, T] ; V_{i}\right), i=1,2$ and $C([0, T] ; V)$ given respectively by

$$
\left\|x_{i}\right\|_{* i}:=\max _{t \in[0, T]} e^{-L_{i} t}\left\|x_{i}(t)\right\| v_{i} \text { and }\|\mathbf{x}\|_{*}:=\max _{t \in[0, T]} \sum_{i=1}^{2} e^{-L_{i} t}\left\|x_{i}(t)\right\| v_{i}
$$

we consider the closed ball $\overline{B_{r}}(0):=\left\{\mathbf{x}=\left(x_{1}, x_{2}\right) \in C([0, T] ; V):\|\mathbf{x}\|_{*} \leqslant r\right\}$, with $r=r_{1}+r_{2}$.

We claim that $\Gamma$ maps $\overline{B_{r}}(0)$ into $\overline{B_{r}}(0)$. In order to prove this, let $\mathbf{y}=\left(y_{1}, y_{2}\right) \in \Gamma \mathbf{x}$ with $\mathbf{x}=\left(x_{1}, x_{2}\right) \in$ $\overline{\mathrm{B}_{\mathrm{r}}}(0)$. From (4.1), we can spot some $\mathbf{h}=\left(\mathrm{h}_{1}, \mathrm{~h}_{2}\right) \in \mathrm{P}_{\mathrm{F}_{1}}(\mathbf{x}) \times \mathrm{P}_{\mathrm{F}_{2}}(\mathbf{x})$ such that

$$
\left\{\begin{array}{l}
y_{1}(t)=e^{A_{1} t} x_{1}^{0}+\int_{0}^{t} e^{A_{1}(t-s)} h_{1}(s) d s \\
y_{2}(t)=e^{A_{2} t} x_{2}^{0}+\int_{0}^{t} e^{A_{2}(t-s)} h_{2}(s) d s
\end{array}\right.
$$

whenever $t \in[0, T]$. Then, for $i=1,2$, (f2) yields the estimate

$$
\begin{aligned}
e^{-L_{i} t}\left\|y_{i}(t)\right\| v_{i} & =e^{-L_{i} t}\left\|e^{A_{i} t} \chi_{i}^{0}+\int_{0}^{t} e^{A_{i}(t-s)} h_{i}(s) d s\right\| v_{i} \\
& \leqslant e^{-L_{i} t}\left\|e^{A_{i} t} \chi_{i}^{0}\right\| v_{i}+e^{-L_{i} t} \int_{0}^{t}\left\|e^{A_{i}(t-s)}\right\|\left\|h_{i}(s)\right\| v_{i} d s \\
& \leqslant M_{i}\left(\left\|x_{i}^{0}\right\| v_{i}+\left\|\psi_{i}\right\|_{L^{1}([0, T])}\right)+M_{i}\left\|x_{i}\right\|_{* i} \int_{0}^{t} e^{-L_{i}(t-s)} \psi_{i}(s) d s .
\end{aligned}
$$

At this point, taking into account that $\mathbf{x} \in \overline{\mathrm{B}_{\mathrm{r}}}(0)$ and (4.3), we are able to find

$$
\sum_{i=1}^{2} e^{-L_{i} t}\left\|y_{i}(t)\right\| v_{i} \leqslant \sum_{i=1}^{2}\left\{M_{i}\left(\left\|x_{i}^{0}\right\|_{v_{i}}+\left\|\psi_{i}\right\|_{L^{1}([0, T])}\right)+M_{i}\left\|x_{i}\right\|_{* i} \int_{0}^{t} e^{-L_{i}(t-s)} \psi_{i}(s) d s\right\} \leqslant \sum_{i=1}^{2} r_{i}=r .
$$

This means that $\|\mathbf{y}\|_{*} \leqslant r$, which proves the claim.

Through Theorem 4.3 for the closed ball $\overline{B_{r}}(0)$, we may thus apply Theorem 2.8 with $M=\overline{B_{r}}(0)$ and $\mathrm{F}=\Gamma$. From Theorem 2.8 we infer that $\mathrm{Fix} \Gamma \neq \emptyset$, so Step 1 holds true. 
2. The solution set of (SEDI) is compact in $\mathrm{C}([0, \mathrm{~T}] ; \mathrm{V})$.

If $\mathbf{x}=\left(\mathrm{x}_{1}, \mathrm{x}_{2}\right) \in \mathrm{C}([0, \mathrm{~T}] ; \mathrm{V})$ is a solution of $(\mathrm{SEDI})$, then for any $t \in[0, T]$ we have that for $i=1,2$,

$$
\left\|x_{i}(t)\right\| v_{i} \leqslant\left\|e^{A_{i} t}\right\|\left\|x_{i}^{0}\right\| v_{i}+\int_{0}^{t}\left\|e^{A_{i}(t-s)}\right\|\left\|h_{i}(s)\right\| v_{i} d s,
$$

with certain $\mathbf{h}=\left(h_{1}, h_{2}\right) \in \mathrm{P}_{\mathrm{F}_{1}}(\mathbf{x}) \times \mathrm{P}_{\mathrm{F}_{2}}(\mathbf{x})$. Then from the growth condition (f2) we obtain that for $i=1,2$,

$$
\begin{aligned}
\left\|x_{i}(t)\right\| v_{i} & \leqslant M_{i}\left\|x_{i}^{0}\right\|_{v_{i}}+M_{i} \int_{0}^{t} \psi_{i}(s)\left(1+\left\|x_{i}(s)\right\| v_{i}\right) d s \\
& \leqslant M_{i}\left(\left\|x_{i}^{0}\right\| v_{v_{i}}+\left\|\psi_{i}\right\|_{L^{1}([0, T])}+\int_{0}^{t} \psi_{i}(s)\left\|x_{i}(s)\right\| v_{i} d s\right),
\end{aligned}
$$

with the constant $M_{i}$ introduced in Step 1 . Now, for $i=1,2$, on the basis of Gronwall inequality, we get the estimate

$$
\left\|x_{i}(t)\right\| v_{i} \leqslant M_{i}\left(\left\|x_{i}^{0}\right\| v_{i}+\left\|\psi_{i}\right\|_{L^{1}([0, T])}\right) e^{M_{i}\left\|\psi_{i}\right\|_{L^{1}([0, T])}}
$$

Therefore $\operatorname{Fix}(\Gamma)$ is bounded in $\mathrm{C}([0, \mathrm{~T}] ; \mathrm{V})$. Due to Theorem 4.3, it turns out that Theorem 2.9 can be invoked by taking $F=\Gamma$ in its statement. We deduce that the solution set of problem (SEDI), which equals $\operatorname{Fix}(\Gamma)$, is compact in $\mathrm{C}([0, \mathrm{~T}] ; \mathrm{V})$. Consequently, the set of all mild trajectories of problem (SEESHVI) is compact in $\mathrm{C}([0, \mathrm{~T}] ; \mathrm{V})$.

3. The solution set of (SEESHVI) is nonempty.

Assertion (b) of Theorem 3.4 guarantees that the set-valued mapping $\mathcal{U}:[0, \mathrm{~T}] \times \mathrm{V} \rightarrow \mathrm{K} v(\mathrm{~K})$ is superpositionally measurable. So, applying Filippov implicit function lemma (see [7, 12]), we conclude that for every trajectory $\mathbf{x}=\left(\mathrm{x}_{1}, \mathrm{x}_{2}\right) \in \mathrm{C}([0, \mathrm{~T}] ; \mathrm{V})$ of (SEDI) there exists a measurable selection $\mathbf{u}(t)=\left(u_{1}(t), u_{2}(t)\right) \in U(t, x(t))$ such that

$$
\left\{\begin{array}{l}
x_{1}^{\prime}(t)=A_{1} x_{1}(t)+f_{1}(t, x(t), u(t)), t \in[0, T] \\
x_{2}^{\prime}(t)=A_{2} x_{2}(t)+f_{2}(t, x(t), \mathbf{u}(t)), t \in[0, T] \\
x_{1}(0)=x_{1}^{0} \text { and } x_{2}(0)=x_{2}^{0}
\end{array}\right.
$$

This ensures that $(\mathbf{x}, \mathbf{u})$ is a mild solution of problem (SEESHVI) in the sense of Definition 1.2. The proof is thus complete.

Remark 4.5. It is worth pointing out that the system (SEDI) of evolutionary differential inclusions includes as a special case the evolutionary differential inclusion (EDI) in [19] because (SEDI) reduces to (EDI) in [19] via choosing suitably the operators $A_{i}$ and $F_{i}$ for $i=1,2$. We first introduce the set-valued mapping $\Gamma: \mathrm{C}([0, \mathrm{~T}] ; \mathrm{V}) \rightarrow \mathrm{Kv}(\mathrm{C}([0, \mathrm{~T}] ; \mathrm{V}))$ in $(4.1)$ and then prove Theorem 4.3 for the upper semicontinuity and $v$-condensing property of $\Gamma$ on every closed bounded subset of $C([0, T] ; V)$. On account of Theorems 3.4 and 4.3 and the fact that the solution set of (SEDI) coincides with the fixed-point set of $\Gamma$, we derive Theorem 4.4 for the compactness of the set of mild trajectories of (SEESHVI) in $\mathrm{C}([0, \mathrm{~T}]$; $\mathrm{V})$. Theorem 4.4 generalizes and extends Theorem 4.4 in [19] from problem (EEVI) in [19] to (SEESHVI).

\section{Acknowledgment}

This research was partially supported by the Innovation Program of Shanghai Municipal Education Commission (15ZZ068), Ph.D. Program Foundation of Ministry of Education of China (20123127110002) and Program for Outstanding Academic Leaders in Shanghai City (15XD1503100). C.-F. Wen was partially supported by the Grant MOST 106-2115-M-037-001. J.-C. Yao was partially supported by the Grant MOST 106-2923-E-039-001-MY3. 


\section{References}

[1] L.-C. Ceng, H. Gupta, C.-F. Wen, Well-posedness by perturbations of variational-hemivariational inequalities with perturbations, Filomat, 26 (2012), 881-895. 1

[2] L.-C. Ceng, N.-C. Wong, J.-C. Yao, Well-posedness for a class of strongly mixed variational-hemivariational inequalities with perturbations, J. Appl. Math., 2012 (2012), 21 pages. 1

[3] X. Chen, Z. Wang, Convergence of regularized time-stepping methods for differential variational inequalities, SIAM J. Optim., 23 (2013), 1647-1671. 1

[4] N. Costea, V. Rădulescu, Hartman-Stampacchia results for stably pseudomonotone operators and nonlinear hemivariational inequalities, Appl. Anal., 89 (2010), 175-188. 1

[5] N. Costea, V. Rădulescu, Inequality problems of quasi-hemivariational type involving set-valued operators and a nonlinear term, J. Global Optim., 52 (2012), 743-756. 3.2

[6] K. Fan, Some properties of convex sets related to fixed point theorems, Math. Ann., 266 (1984), 519-537. 2.1

[7] A. F. Filippov, On some problems of the theory of optimal control, Vestn. Moscow Univ., 2 (1958), 25-32. 4

[8] F. Giannessi, A. Khan, Regularization of non-coercive quasivariational inequalities, Control Cybern., 29 (2000), 91-110. $2,2.12$

[9] J. Gwinner, On the p-version approximation in the boundary element method for a variational inequality of the second kind modelling unilateral control and given friction, Appl. Numer. Math., 59 (2009), 2774-2784. 1

[10] J. Gwinner, On a new class of differential variational inequalities and a stability result, Math. Program., 139 (2013), 205-221. 1

[11] L. Han, J.-S. Pang, Non-Zenoness of a class of differential quasi-variational inequalities, Math. Program., 121 (2010), 171-199. 1

[12] M. Kamemskii, V. Obukhovskii, P. Zecca, Condensing Multivalued Maps and Semilinear Differential Inclusions in Banach Space, Walter de Gruyter, Berlin, (2001). 2, 2, 2, 2, 2, 4, 4, 4

[13] A. A. Khan, D. Motreanu, Existence theorems for elliptic and evolutionary variational and quasi-variational inequalities, J. Optim. Theory Appl., 167 (2015), 1136-1161. 3.2

[14] X.-S. Li, N.-J. Huang, D. O'Regan, Differential mixed variational inequalities in finite dimensional spaces, Nonlinear Anal., 72 (2010), 3875-3886. 1

[15] Z. Liu, Browder-Tikhonov regularization of non-coercive evolution hemivariational inequalities, Inverse Problems, 21 (2005), 13-20. 1

[16] Z. Liu, X. Li, D. Motreanu, Approximate controllability for nonlinear evolution hemivariational inequalities in Hilbert spaces, SIAM J. Control Optim., 53 (2015), 3228-3244. 1

[17] Z. Liu, N. V. Loi, V. Obukhovskii, Existence and global bifurcation of periodic solutions to a class of differential variational inequalities, Internat. J. Bifur. Chaos Appl. Sci. Engrg., 2013 (2013), 10 pages. 1, 4.1

[18] Z. Liu, B. Zeng, Existence results for a class of hemivariational inequalities involving the stable ( $\mathrm{g}, \mathrm{f}, \alpha)$-quasimonotonicity, Topol. Methods Nonlinear Anal., 47 (2016), 195-217. 3.2

[19] Z. Liu, S. Zeng, D. Motreanu, Evolutionary problems driven by variational inequalities, J. Differential Equations, 260 (2016), 6787-6799. 1, 3.2, 4.5

[20] S. Migórski, A. Ochal, M. Sofonea, Nonlinear Inclusions and Hemivariational Inequalities. Models and Analysis of Contact Problems, Springer, New York, (2012). 1, 2, 2

[21] D. Motreanu, P. D. Panagiotopoulos, Minimax Theorems and Qualitative Properties of the Solutions of Hemivariational Inequalities and Applications, Kluwer Academic, Dordrecht, (1999). 1

[22] Z. Naniewicz, P. D. Panagiotopoulos, Mathematical Theory of Hemivariational Inequalities and Applications, CRC press, New York, (1994). 1

[23] P. D. Panagiotopoulos, Nonconvex superpotentials in sense of F.H. Clarke and applications, Mech. Res. Comm., 8 (1981), 335-340. 1

[24] P. D. Panagiotopoulos, M. Fundo, V. Rădulescu, Existence theorems of Hartman-Stampacchia type for hemivariational inequalities and applications, J. Global Optim., 15 (1999), 41-54. 1

[25] J.-S. Pang, D. E. Stewart, Differential variational inequalities, Math. Program., 113 (2008), 345-424. 1, 4.1

[26] D. Repovš, C. Varga, A Nash type solution for hemivariational inequality systems, Nonlinear Anal., 74 (2011), $5585-$ 5590. 1

[27] X. Wang, N.-J. Huang, A class of differential vector variational inequalities in finite dimensional spaces, J. Optim. Theory Appl., 162 (2014), 633-648. 1

[28] Y.-M. Wang, Y.-B. Xiao, X. Wang, Y. J. Cho, Equivalence of well-posedness between systems of hemivariational inequalities and inclusion problems, J. Nonlinear Sci. Appl., 9 (2016), 1178-1192. 1, 1, 2, 2.11, 3, 3

[29] Y.-B. Xiao, N.-J. Huang, Browder-Tikhonov regularization for a class of evolution second order hemivariational inequalities, J. Global Optim., 45 (2009), 371-388. 1

[30] Y.-B. Xiao, N.-J. Huang, Well-posedness for a class of variational-hemivariational inequalities with perturbations, J. Optim. Theory Appl., 151 (2011), 33-51. 1, 2

[31] Y.-B. Xiao, N.-J. Huang, J. Lu, A system of time-dependent hemivariational inequalities with Volterra integral terms, J. Optim. Theory Appl., 165 (2015), 837-853. 1 
[32] Y.-H. Yao, N. Shahzad, An algorithmic approach to the split variational inequality and fixed point problem, J. Nonlinear Convex Anal., 18 (2017), 977-991.

[33] H. Zegeye, N. Shahzad, Y.-H. Yao, Minimum-norm solution of variational inequality and fixed point problem in Banach spaces, Optimization, 64 (2015), 453-471. 1

[34] E. Zeidler, Nonlinear Functional Analysis and Its Applications, Springer-Verlag, New York, (1990). 2, 2.3, 3, 3

[35] Y. Zhang, Y. He, On stably quasimonotone hemivariational inequalities, Nonlinear Anal., 74 (2011), 3324-3332. 1 